\title{
Investors care about risk, but can't cope with volatility
}

\author{
Christian Ehm* Christine Kaufmann ${ }^{* *} \quad$ Martin Weber***
}

October 10, 2011

\begin{abstract}
Following the classical portfolio theory all an investor has to do for an optimal investment is to determine his risk attitude. This allows him to find his point on the capital market line by combining a risk-free asset with the market portfolio. We investigate the following research questions in an experimental set-up: Do private investors see a relationship between risk attitude and the amount invested risky at all and do they adjust their investments if provided with different risk levels of the risky asset? To answer these questions we ask subjects in a between subject design to allocate a certain amount between a risky and a risk-free asset. Risky assets differ between conditions, but can be transformed into each other by combining them with the risk-free asset. We find that mainly investors risk attitude, but also their risk perception, and the investment horizon are strong predictors for risk taking. Indeed, investors do not appear to be naïve, but they do something sensitive. Nevertheless, we observe a strong framing effect: investors choose almost the same allocation to the risky asset independently of changes in its risk-return profile thus ending up with significantly different volatilities. Feedback does not mitigate the framing effect. The effect is somewhat smaller for investors with a high financial literacy. Overall, people seem to use two mental accounts, one for the risk-free and one for the risky investment with the risk attitude determining the percentage allocation to the risky asset and not the chosen portfolio volatility.
\end{abstract}

\footnotetext{
*University of Mannheim, Chair of Banking, contact: ehm@bank.bwl.uni-mannheim.de

${ }^{* *}$ University of Mannheim, Chair of Banking, contact: kaufmann@bank.bwl.uni-mannheim.de

*** University of Mannheim, Chair of Banking and CEPR, London. contact: weber@bank.bwl.unimannheim.de

We thank Daniel Foos, Markus Glaser, Dan Goldstein, Thomas Langer, Daniel Smith, and Sascha Steffen, as well as all seminar participants at the 2nd Annual Boulder Summer Conference on Financial Decision Making, the SPUDM conference 2011, the LMU Munich, the University of Mannheim, and the University of Münster. We are grateful to the German Consumer Protection Agency (Verbraucherzentrale Bundesverband) for hosting a common press conference leading to significant media coverage and the promotion of our on-line questionnaire and to Dominic Hiller for programming the experiment.
} 


\section{Introduction}

One of the central questions in investing is how much risk to take; theoretically, this question is easy to answer. According to basic financial theory, the efficient frontier of investment opportunities in a mean-variance-framework is defined by the capital market line (Tobin, 1958), the line through the risk-free rate forming a tangent to the set of risky investments. The capital market line offers some central insights (Sharpe, 1964; Lintner, 1965; Mossin, 1966; Treynor, 1962):

- more expected return requires the investor to take on more risk, which is defined as standard deviation (volatility),

- risk and return are linearly related,

- there is one risky asset (market portfolio)for all investors - independent of the investor's risk attitude.

All an investor has to do to find the optimal investment alternative is to assess his risk attitude. Risk attitude directly leads to the allocation between the risk-free asset and the risky asset: higher risk aversion will result in a higher proportion invested into the risk-free asset. ${ }^{1}$

This paradigm is relevant not only from a theoretical perspective, but also has large practical implications. According to the European MiFiD directive (European Parliament and European Council, 2004; European Parliament and European Council, 2006), the risk attitude of each European investor seeking investment advice needs to be assessed and the investment alternative recommended has to be in accordance with this risk attitude. More recently, the new European UCITS directive (European Parliament and European Council, 2009) requires a key investor information document (KIID) for a large class of investment alternatives: in this two page flyer risk and return have to be described, with risk defined as standard deviation ${ }^{2}$ just as in the Markowitz model. All banks and investment advisers in Europe are required to fulfill these requirements. Two questions follow immediately:

1. Do investors see a relation between their stated risk attitude and the amount invested into a risky portfolio?

2. In choosing a simple portfolio, are investors subject to framing effects when given portfolios with different riskiness (i.e. volatilities)?

Let us explain the idea using a simple example: an important question in real life is how much sugar to take in one's coffee. In case we like to know more about people's capability to determine the subjectively "right" amount of sugar, we could first ask

\footnotetext{
${ }^{1}$ Note, that the central role of risk attitude to determine the optimal portfolio is also true in other models than the mean-variance model (see e.g. Merton, 1969).

${ }^{2}$ The volatility of returns is presented as a simplified risk indicator with seven categories to which the products are assigned to based on their historical volatility.
} 
if people understand the relationship between "I want to have my coffee sweeter" and "putting more sugar into it" (similar to question 1). Next, we would be interested in determining the extent to which the concentration of sweetness is related to the amount chosen, e.g. if you take sweetener (where the same amount has a higher concentration of sweetness) instead of crystal sugar. Of course, we should be able to adjust the amount of sugar, thus independently finding the optimal sweetness for the coffee. Another analogy would be the question to what extent the size of the spoon is related to the amount of sugar taken. In this case we should be able to end up with the same amount of sugar and adjust for the size of the spoon. This should be the case especially if we have the possibility of tasting the coffee during the procedure

To answer these two research questions, we use a standard design often employed in the analysis of financial decision making under risk (Gneezy and Potters, 1997; Frijns et al., 2008; Nosic and Weber, 2010). Borrowing from the idea of the capital market line, we ask subjects to allocate a stated amount of money between a risk-free and a risky asset, whereas subjects were able to choose between three amounts and investment horizons to set the investment context close to their personal circumstances. The riskreturn profile of the risky asset as well as the chosen portfolio provided to the subjects by means of an interactive computer simulation which allows them to experiencing the return distributions (cf. Haisley et al., 2011). In addition, we ask subjects to state their risk attitude allowing us to analyze our first research question. To answer our second research question we vary the risky asset subjects could invest into in a between-subject design. One group of subjects was asked to invest into a "market portfolio", a second and a third another one to invest into a risky asset (about) twice or half as risky as the market portfolio. As the assets could have been transformed into each other by combining them with the risk-free asset, we are able to measure the influence of framing an asset more or less risky on risk taking and risk judgment.

Our study is related to different fields of research. Research on risk judgments until now has provided several insights with regard to the influence of risk preferences on risk taking. We know that risk attitude is domain-specific (e.g. E. Weber et al. (2002); Vlaev et al. (2009); Nosic and Weber (2010)), that is to say a risk attitude measured in one domain (e.g. sports) is not necessarily related to a risk attitude in another domain (e.g. the financial domain). Even within the financial domain risk attitude measured through means of lottery decisions has been found to be less predictive for investment decisions than a simple question about the willingness to take on financial risk on a Likert Scale (e.g. Dorn and Huberman, 2005, 2010), which we hence use in our experiment. This question not only allows us to link preferences to behavior, but also to investigate whether investors do something sensible. Research has shown that participants often use simple heuristics, when decisions get more complex. One famous example is known as the $1 / n$ heuristic - participants distribute their investments equally over the set of available assets, no matter whether those consist mainly of stock funds or of bonds funds, resulting in vastly different risk-return profiles in the overall portfolio (Benartzi and Thaler, 2001). Apart from using heuristics, subjects are also very prone to general framing effects (e.g. Tversky and Kahneman, 1981) in financial decision making. People perceive assets to be 
less risky if names are included (E. Weber et al. (2005)) and risk perceptions differ if the riskiness is presented in different formats (e.g. Haisley et al., 2011; Diacon and Hasseldine, 2007), e.g. in bar charts versus distributions. In our setting we are able to link the different findings on risk judgments and perceptions to a framing effect on objective risk measures, namely volatility, and analyze subjects' behavior in more detail. We focus on individual differences in risk taking behavior and analyze its variation between subjects, taking into account different personal traits (risk attitude or financial literacy).

Subjects were recruited from the general population through newspaper articles and radio station reports in a joint campaign with the German Consumer Protection Agency ("Verbraucherzentrale Bundesverband"). Overall, 1,958 people participated in our online experiments; subjects had a $25 \%$ chance of being paid proportionally to their performance.

We find that people are able to state their risk attitude and that this risk attitude is strongly related to the percentage amount invested into the risky asset. Our participants on average invest $60 \%$ into the risky asset but individually vary their allocation widely in accordance with their stated risk attitude; in addition, people act in a sensible way. We replicate results from the previous literature: a longer time horizon leads to riskier investments (Klos et al., 2005; Siebenmorgen and Weber, 2004), lower volatility and lower perceived risk also result in a higher allocation to the risky asset (Nosic and Weber (2010), E. Weber et al. (2002)).

The answer to our second research question is rather astonishing: we find a perfect framing effect. Subjects on average did not adjust for the volatility of the risky investment at all, i.e. they take the same amount of sugar independently of its sweetness or the size of the spoon. This is even more surprising as we interactively simulate the distribution of the risky asset as well as the chosen portfolio, i.e. we let them taste the sweetness of the coffee. We also ask subjects for the riskiness of the risky asset and cannot observe any significant difference even if the volatility differs by a factor of two or four. If we only consider participants who are more knowledgeable (higher financial literacy or employed in financial industry) we find significant adjustments; these adjustments are, nevertheless still far away from resulting in portfolios with the same risk-return profile.

As a further test, we give to one additional group of participants another risky asset that dominates the basic asset. The results are similar; people seem to have risk preferences for their investments. However, they seem to use two mental accounts (see e.g. Thaler, 1999) when deciding on their allocation; they divide their portfolio into "risk-free investment" and "risky investment" and do not adjust their investment decision for the riskiness (volatility) of the second account; results hold although we let people experience the return distribution of their investment.

Our contribution to the literature is threefold; first, we combine the flood of details that is known about risk-attitude and risk-taking. While most papers investigate details on the relationship between stated risk preferences, personal traits, demographics and the chosen asset allocation, we combine these details enabling us to extend findings of other studies like Benartzi and Thaler (2001) to an analysis on an individual level. Second, we document a very strong framing effect and are able to analyze risk preferences and risk taking behavior as well as its changes by changes in riskiness simultaneously. Our 
framing does not stem from manipulations that should only affect subjective perceptions but results from framing of objective numbers, namely the volatility: we set different anchors in the sense of different risk levels provided. However, the manipulation still reflects framing as the results of the decisions can be economically the same - by moving them up and down the capital line, the portfolios we provide can be transformed into each other. We find that investors are not able to fulfill this task, even if it is central for investing. Third, we obtained these results although subjects were given frequent feedback in an easily understandable form. In the words of our example: Investors taste their coffee, but they don't adjust the amount of sugar when providing it with a higher concentration or volume of sweetness.

Our results have major policy implications. It seems that people either do not understand the information provided or have another risk concept in mind when deciding on their asset allocation. The concepts of randomness and probability seem to be more difficult than researchers and regulators think so far. Even when provided with a simulation, subjects are not able to independently evaluate the riskiness of an investment. One possibility for solving this problem is to educate or patronize people even more: Participants could be shown different distribution functions or could be helped by being provided with easier understandable risk indicators in the way the EU regulation is currently suggesting. We discuss these implications as well as ideas for future research in the discussion section.

The remainder of the paper is organized as follows. After a short literature review (section 2) we present the design of our study (section 3). In Section 4 we address the relationship between risk attitude and risk taking (question 1) whereas Section 5 focuses on the influence of riskiness of the risky asset provided on risk taking (question 2). Section 6 summarizes and discusses policy implications and ideas for future research.

\section{Literature Review}

There is a large literature on how investors should choose their preferred portfolio out of the universe of available assets versus how they do choose it. With regard to classical portfolio theory following Markowitz (1952), investors differ only with respect to the extent that they are trading off return against volatility. According to the two-fund separation theorem of Tobin (1958) all investors should hold a combination of the same risky efficient market portfolio and a risk-free asset, whereas the actual split is determined by the individual's risk attitude. Empirical findings show, however, that investors' behavior in practice is different. A phenomenon known as the equity premium puzzle (Mehra and Prescott, 1985; Benartzi and Thaler, 1995) describes that the low participation rate in stocks markets cannot be explained by investors' risk aversion taking the strong outperformance of stocks over bonds into account. Canner et al. (1997) find in their study that investors additionally are not advised to allocate their money between a risky and a risk-free fund, but instead to adjust their bond to stock ratio dependent on their risk attitude; this contradicts classical finance theory, as they vary the composition of the 
risky asset and not the allocation between the risky and the risk-free asset). ${ }^{3}$ In our study, an asset-allocation decision in line with the fund separation theorem is presented. Subjects face a trade-off between risk and return by having to allocate an endowment between a risky and a risk-free asset. We then analyze how investors in general determine their point on the capital market line as well as the effect of setting different starting points on this line by providing different risky assets.

The literature shows that people do not always act in accordance with classical finance theory; this does not mean, however, that they behave randomly. Risk taking can be explained and predicted by various factors (Frijns et al., 2008). The literature has shown that these factors are driven more by subjective beliefs and expectations than by objective risk indicators (see e.g. Sarin and Weber, 1993; Jia et al., 1999). Two of the key explanatory variables in those behavioral models are risk attitude and risk perception. The influence of these traits varies tremendously dependent on the situational context and the domains they are assessed in. Risk attitude itself has been found to be a quite stable construct over time (Sahm, 2007; Baucells and Villasís, 2010; Nosic and Weber, 2010; Klos, 2011); however, it varies across domains (E. Weber et al. (2002)). Even within the financial domain, risk attitude changes, as evidenced for instance by the fact that preferences elicited with the help of lotteries differ from those elicited in a portfolio choice setting (Vlaev et al., 2009; Nosic and Weber, 2010). We hence use self-assessed risk attitude measured by a simple question asking for the willingness to take financial risk; simple questions have been shown to be predictive for financial risk taking (Kapteyn and Teppa, 2009; Dorn and Huberman, 2010). Risk perception, on the other hand, is not a stable trait, but instead influenced by various factors and seems to mediate the relationship between risk taking and contextual factors (e.g. Sitkin and Weingart, 1995; Sitkin and Pablo, 1992). Studies have shown that measuring risk perception and risk attitude results in greater cross-situational stability of risk preferences (E. Weber and Milliman (1997); E. Weber et al. (2002)) and therefore improves explanatory power. In this study, both variables are used to address the first research question.

Apart from the influence of personal traits and preferences, risk taking depends on the decision context. There are two phenomena documented in the literature which can serve as an explanation for our results: the first is known as anchoring and adjustment, the second is known as framing. Anchoring and adjustment means that subjects start with an initial value (anchor) and come to their final decision by means of an adjustment in either direction, based on additional information and further thinking. However, this adjustment is mostly insufficient and the final decision depends strongly on the anchor which has been set, for example by a certain presentation format, the formulation mode, or the elicitation mode (Tversky and Kahneman, 1974). Anderson and Settle (1996) analyze portfolio choice decisions and find that anchoring is one possible reason for the final choice; they provide both annualized returns and ten-year returns for a ten-year investment horizon and find that the adjustment for the different returns (yearly vs.

\footnotetext{
${ }^{3}$ Apart from that it has been known for some time, that investors do not construct their market portfolio optimally when provided with multiple assets (Kroll et al. (1988b,a); however the construction of the market portfolio is not the focus of our study.
} 
ten-year) is insufficient. This is different from our experiment as we use another form of anchor: subjects start with different risky assets.

A decision frame is described as "the decision-maker's conception of the acts, outcomes, and contingencies associated with a particular choice" (Tversky and Kahneman, 1981). A different framing of the same decision problem can have an influence on preferences and behaviour. Inconsistent reactions to different decision frames have been observed in several studies. Diacon and Hasseldine (2007) for instance show for example that risk perception is influenced by the presentation format (past return information as fund values versus percentage yields). In our experiment three risky assets are considered, all of which could be transferred into each other by the participants; subjects are hence in a similar decision context. The assets are each a combination of the risky and the risk-free asset, with only the part already invested into the risky asset differing.

Our analysis is also related to the literature on heuristics in decision making. Naïve diversification (Benartzi and Thaler, 2001) describes investors' allocations in retirement plans. The authors show that, on average, investors divide their contributions evenly between the different funds offered in the plan. As a consequence, the riskiness of the portfolio depends strongly on the riskiness of the products offered - a higher fraction of equity funds compared to bond funds for instance results in a higher portfolio risk: investors investing in a stock and a bond fund (not labelled as such) on average allocate 54 percent to the stock fund; investors investing in a balanced fund (with substantial lower volatility compared to the stock fund) and a bond fund allocate 57 percent to the balanced fund. In our study, a simpler decision context (the choice between a risky and a risk-free investment) is analyzed; furthermore, instead of the group level, the individual level is analyzed in our study.

We additionally investigate whether the effects found are mitigated by financial knowledge. Kaustia et al. (2008) find that students are more prone to anchoring than professionals and that this effect is diminished for students with stock market experience that have taken finance courses. While the authors show that the anchor effect can be attenuated by experience, the effect itself is observed across all groups of participants. In accordance with these results, Müller and Weber (2010); Campbell (2006); Calvet et al. (2007) find that more financially sophisticated households and individuals invest more efficiently. We control for financial literacy, for stock market experience and for whether participants work in the financial industry.

\section{Data}

\subsection{Experimental Task}

In our study, participants were asked to allocate a certain investment amount between a risk-free asset and a risky asset. Figure 1 gives a graphical overview of the experimental design.

\section{Insert figure 1 here.}


At the beginning of the experiment, participants had to choose an investment amount (either $€ 5,000, € 50,000$, or $€ 100,000$ ) and a time horizon (either one, five, or ten years). When pretesting the design with a fixed investment environment, several participants reported that the investment context was not familiar as the investment amount was too high or too low or the investment horizon was too long or too short. Consequently, participants were allowed to choose a decision context that was as close as possible to individual circumstances. All participants choosing the same time horizon received the same risk-free asset, whose return was based on the actual interest rates for time deposits in July 2010 when the experiment was conducted (see table 1).

\section{Insert table 1 here.}

Subjects were randomly assigned to one of six different treatment conditions. The conditions presented differed in the risk-return profile of the risky asset; the different risk-return combinations are summarized in table 2 .

\section{Insert table 2 here.}

The focus of the analysis is on the first three conditions (referred to as the "main conditions") whose risky assets are easily comparable. The three remaining risky assets are used for additional ancillary analyses and robustness checks ("ancillary conditions"). The risky assets in the main conditions all approximately lie on the same line in a $\mu$ $\sigma$-diagram which means that they can theoretically be transformed into one another by combining them with a risk-free asset. The first risky asset is based on historical monthly returns of the German stock index DAX from 1973 to 2009. Subjects are not told that they face the DAX but instead only about a diversified fund. The no-name DAX condition is referred to as the "basic condition" or as the "basic asset".

The second and third assets are also based on the returns of the DAX; they nearly lie on the same line in the $\mu$ - $\sigma$-diagram; their return distributions are constructed from the DAX returns by combining the DAX with a risk-free asset. As compared to the basic asset, the second asset's return and risk are reduced by replacing some of the DAX's share with this risk-free asset; the resulting condition is referred to as the "de-levered condition" or the "de-levered asset". The third condition's return and risk are increased by lending at the respective risk-free rate and increasing the DAX's share above $100 \%$ ("levered asset" or the "levered condition").

We decided to use the historical Frankfurt Interbank Offered Rates (FIBOR) as the risk-free asset. ${ }^{4}$ For every month, a new return is computed by combining the historical FIBOR with the historical DAX return. There are three possibilities: an arbitrary percentage combination (e.g. 50\% DAX and 50\% FIBOR), a target volatility for the resulting asset that implicitly determines the percentages, and a target return for the

\footnotetext{
${ }^{4}$ For the return of the risk-free asset used, one has to decide between a fixed rate and historical riskfree returns that fluctuate over time. Historical interest rate fluctuations may not be independent from historical DAX returns, e.g. both risk-free returns and stock returns were very high after the reunification of Western and Eastern Germany. Additionally historical returns are more realistic as investors could really have faced these returns.
} 
resulting asset that determines the percentages. Note that the exact standard deviation and the exact return of the resulting market portfolios do not matter as long as they differ sufficiently from the ones of the basic asset. The standard deviation of the dominating asset described later has been chosen as the target value for the de-levered asset and its return has been chosen as the target value for the levered asset. Both of the assets constructed are comparable to the basic asset as they share a common distribution of stock returns. Subjects can approximately transform one into the other by combining it with the risk-free asset they are provided with.

The three ancillary conditions (see table 2 for an overview) are used to test the robustness of our results and to investigate interactions with known phenomena. The first of these additional risky assets dominates the three assets described above as it has a lower risk and/or a higher return than the main assets. We refer to this asset as the "dominating asset" or the "dominating condition"; it's risk-return profile is based on historical returns of "the world portfolio" described by Jacobs et al. (2010). The second ancillary condition shares the return distribution of the dominating asset but participants receive additional information on the asset; they are told that they face a world index invested into common stock $(60 \%)$, bonds $(25 \%)$, and commodities $(15 \%)$. It can be inferred from this information that the asset is broadly diversified. The third ancillary condition shares the return distribution with the basic condition. Additionally, participants in the "DAX (name) condition" are told that they face the DAX and that the DAX is a pure stock index which contains the 30 largest German companies according to market capitalization.

Having been assigned to one of the six conditions, subjects were informed about the return of the risk-free asset and about the risk-return profile of the risky asset separately before taking an allocation decision. Information about the potential returns of the assets was provided via a risk simulation tool.

\section{Insert figure 2 here.}

This risk tool has been introduced in a study conducted by Haisley et al. (2011) and has been developed to communicate asset risk with the help of experience sampling and graphical displays. Haisley et al. (2011) show that the use of the risk tool in comparison to the use of other methods for presenting asset risk (description, distribution graphs, and pure experience sampling) leads to greater recall abilities and subjective comprehension, higher risk taking without any increase in decision regret, and less reactivity to either positive or negative variations in returns. The risk tool works as follows: Participants see the expected returns and potential outcomes of their investment on a graphical interface. With a single line indicating that the return is guaranteed without any variance, they are first shown the return of the risk-free asset before they are shown the expected return and variance of the risky asset. The program randomly draws potential returns out of the underlying distribution (see figure 2(a)). The whole distribution is built up bit by bit with each draw contributing to a distribution function on the screen. It is explained that a higher bar in the distribution reflects a higher probability for the respective outcome. Participants are allowed to sample for as long as they want (at most until the entire 
distribution is built up), but they are required to sample at least sixteen draws (eight in a slow mode, eight in a fast mode). The picture of the full distribution that is shown at the end of the simulation includes markers at the amount invested and at the expected outcome highlighting this key data (see figure 2(b)). The return scale shown in the distribution diagram is the same for all conditions with the same investment amount and the same time horizon, meaning that a person assigned to a condition with a riskier asset will also see a more widespread distribution function.

After the illustration of the two assets, participants are asked to choose an initial allocation between the two assets; they are told that they will have the possibility to adjust this allocation afterwards. The percentage allocation can be chosen from the range of $0 \%$ to $100 \%$; lending, which would lead to an allocation above $100 \%$, is not allowed. Most private investors have the possibility to take on credits and loans, so it might make sense to allow this; however, as subjects already face a complex decision, we have decided not to complicate it any further by adding a lending possibility. Additionally, investors are often advised against buying risky assets on loan; for that reason, even subjects that would have understood the design, might have been reluctant to take out loan, thus affecting the results. While these problems are circumvented by omitting a lending possibility, the results do not lose generality (this issue is considered in more detail in sections 4 and 5).

To give subjects a feeling for the riskiness of their choice, they also see the expected value and quantiles of the portfolio profile based on their chosen allocation. The two lines incorporated into the graphical interface enclose $70 \%$ of all possible outcomes; additionally, two lines that enclose $95 \%$ of all possible outcomes are added (see figure 2(c)). ${ }^{5}$ Analogously to the presentation of the risky asset, the portfolio resulting from the initial allocation decision is then simulated using the risk tool. Afterwards, subjects can change their allocation and try as many different allocations as they want. When they fell that they have seen enough information, they are asked to give their final allocation decision. The participants are incentivized to state their real preferences: they are told that 500 participants will win an amazon.com gift card whose amount depends on the chosen allocation to the risky asset. It is explained that a "financial market simulation" will be run at the end of the experiment to determine the return of their investment after the chosen investment period. It is explained that this return will be drawn randomly from the distribution of returns and that they determine this distribution with their allocation decision.

Subsequently, participants are asked for some personal characteristics. Participants first provide their self-reported risk attitude on a 1-7 scale and answer questions on their age, gender, education, and income.

Questions measuring subjects' knowledge, abilities, and familiarity with portfolio allocation decisions then follow. A direct measure for knowledge is financial literacy; consequently, the set of advanced literacy questions from van Rooij et al. (2011) is used

\footnotetext{
${ }^{5}$ If the historical returns were normally distributed, the first two lines would indicate the expected outcome plus around one standard deviation and the expected outcome minus around one standard deviation while the second two lines would indicate plus/minus two standard deviations
} 
to control for this effect. Stock market participation and employment in the financial industry are also elicited.

\subsection{Participants \& Descriptives}

Participants are recruited from the German population via articles in various German newspapers (nationwide ones like Tagesspiegel or Börse Online as well as regional newspapers), reports on various German radio stations (e.g. Deutschlandfunk), and information from a behavioral finance e-mail newsletter. The articles have been published following a press release which includes a link to our on-line-experiment. The press release explains new EU regulation on mutual funds and the description of fund risk herein. People are offered a summary of their results and a classification of their chosen portfolio in terms of the seven risk buckets that are also used by the EU key investor information document. Journalists are explicitly asked not to describe the experiment in more detail so as not to influence the results. Newspaper articles and reports on the radio have been screened for information that exceeds the information given in the press release but no further information has been found. Overall, 2105 participants have completed the survey. Datapoints that appear to result from a person's repeated participation are manually deleted. The resulting dataset consists of 1958 participants.

The median income range is $€ 30,000$ - $€ 50,000$, which fits the German average $(€ 33,700$ (see table $3(\mathrm{a})$ ). Around fifty-two percent are college educated (graduate-level and Ph.D.-level), which is clearly above the German average of nearly $14 \%$ (see table $3(\mathrm{~b}))$. The remaining summary statistics can be found in table 3(c). The average of the stated risk attitude is also higher than the German average. Participants have high financial knowledge on average and over eighty percent own stocks (German average: $25 \%$ ). The participants are significantly younger than the average German, there is a high number of male participants, and financial professionals seem to be overrepresented. While this indicates that the sample is not representative for the German population, it does not mean that the results lose generality; all relevant variables indicate that participants in the sample are more familiar with financial decision making. If there is a selection bias, it will only lead to subjects' decisions appearing to be better/more rational. Results indicate that even participants in this sample (who should perform better) are not able to take consistent decisions. Nevertheless, the sample is split controlling for such effects when performing analyses.

\section{Insert table 3 here.}

Investment amounts are almost equally distributed across participants (see table 4(a)). The investment amount chosen increases with age, male gender, income, education, financial knowledge, and a preference for saving (regressions not reported). Across all conditions almost fifty percent of participants choose a time horizon of five years for their investment (see table 4(b)). The chosen time horizon increases with education, employment in the financial industry, lower risk aversion, participation in the stock market, financial knowledge, and a preference for saving (regressions not reported). The selection 
issue for investment amount and investment horizon is addressed in more detail in the following sections.

\section{Insert table 4 here.}

\section{The Relationship between Risk Attitude and Risk Taking}

Across all conditions, participants on average allocate $59.8 \%$ to the risky asset. The distribution of percentage allocations seems to be wide spread and does not look unusually distributed (see figure 3). Participants show a preference for rounding to the nearest ten percent: $25 \%$ of the participants use multiples of ten for their allocation. Similar effects have been shown in the literature (e.g. Huberman and Jiang, 2004). The high fraction of participants investing $100 \%$ into the risky asset is due to the experimental design; whenever a participant were to prefer an allocation above $100 \%$, he should choose exactly $100 \%$. Overall, the distribution pattern does not give the impression that subjects were using naïve diversification by simply investing 50:50 - only $11 \%$ of the participants choose an allocation consistent with this kind of strategy, while Benartzi and Thaler (2001) report numbers between $21 \%$ and $34 \%$. Reasons for this considerable difference may be found in the different experimental designs: While Benartzi and Thaler (2001) offer a choice between a bond fund and a risky fund, we offer a choice between a riskfree asset and a risky fund, and while Benartzi and Thaler (2001) use fixed graphical displays, we simulate the assets in more detail. Another reason might be the fact that our subjects are quite financially literate (the effects of financial literacy will be discussed in more detail later).

\section{Insert figure 3 here.}

Having considered risk taking itself, we shall now focus on risk attitude as its main explanatory variable. Participants on average report a risk attitude of 4.23 on a scale of one to seven ( $1=$ not willing to accept any risk; $7=$ willing to accept substantial risk). The mean allocation to the risky asset (i.e. actual risk taking) is monotonically increasing in the risk attitude (see figure 4): for instance, participants reporting a risk attitude of 2 $(\mathrm{n}=189)$ allocate an average of $39.6 \%$ to the risky asset, whereas participants reporting a risk attitude of $6(\mathrm{n}=281)$ on average allocate $74.1 \%$ to the risky asset. This difference is significant $\left(t_{468}=15.99, p=0.00\right)$. Out of 21 pairwise differences, nineteen differences are statistically significant $(p=0.00) .{ }^{6}$ We find an increasing allocation for higher risk attitudes. ${ }^{7}$ Differences between risk attitudes are highly significant in almost all

\footnotetext{
${ }^{6}$ The difference between allocations for risk attitude 6 and 7 is significant with $p<0.05$ and the difference for risk attitude 1 and 2 is not significant $(p=0.158)$, which is due to the small number of participants with a risk attitude of 1 .

${ }^{7}$ Except for risk attitudes 1 and 7 in the de-levered condition. The inconsistent values are driven by outliers together with small sample sizes ( 5 and 14 observations respectively). Differences between conditions are analyzed in more depth in the next section.
} 
cases. $^{8}$ The correlation between allocation and risk attitude is equal to 0.455 and is highly significant $(\mathrm{p}<0.01)$, also implying a strong relation between these two variables. At first glance, these univariate results hence support the notion that an investor's risk attitude is strongly related to the percentage he chooses to invest into the risky asset.

\section{Insert figure 4 here.}

In order to formally test this relationship in a multivariate setting, an OLS regression with allocation to the risky asset as the dependent variable is used. ${ }^{9}$ The results confirm the findings of the univariate analysis and show that participants behave in accordance with their stated preferences: risk attitude significantly predicts risk taking (see table 5); a one level increase on the risk attitude scale results in an increase of $7 \%$ in the allocation to the risky asset (which is in line with previous findings, e.g. Dorn and Huberman, 2005, 2010). Additionally, investors tend to reduce their allocation to the risky asset with a higher perceived risk, which is also in line with the literature (Sitkin and Pablo (1992); Nosic and Weber (2010), E. Weber and Milliman (1997)): a one level increase in risk perception of the risky asset results in an allocation decrease of $4 \%$.

An increase in investment horizon ${ }^{10}$ or in investment amount leads to higher risk taking, which also shows that participants do something sensible: facing a ten year time horizon instead of a one year time horizon, the probability of receiving an outcome below the amount invested decreases from $36.5 \%$ to $16 \%$. The probability of receiving a return below the risk-free return decreases from $38.5 \%$ to $31.5 \%{ }^{11}$ The free choice of investment horizon and investment amount should not lead to endogeneity as they are both chosen before participants have any information on the assets and before they make their allocation decisions. ${ }^{12}$

As they differ between conditions, the annual expected return and volatility of the risky assets are added as further control variables; both are significant predictors of risk taking. Consistent with previous results (e.g. Croson and Gneezy, 2009; Nosic et al., 2011), women appear to be more risk averse than men, albeit this relationship is significant only at the 10\%-level. Participation in the stock market and education are also controlled for, but these variables have no significant effect on risk taking. ${ }^{13}$

\footnotetext{
${ }^{8}$ Only when sample sizes are low and risk attitudes are close at the same time, significance vanishes. Lets take the basic condition as an example: the difference in allocation for participants with the risk attitude 1 ( 7 subjects) and those with risk attitude 2 (33 subjects) is not significant. However the difference for risk attitude 1 ( 7 subjects) vs. 3 ( 55 subjects) is significant again $(p=0.01)$.

${ }^{9}$ As allocation is limited to the interval from 0 to 1 , a Tobit regression model is used to confirm the results. Results do not qualitatively differ in the Tobit model; consequently only the results of the OLS model are described.

${ }^{10}$ Results do not change if the risk-free return is used as a control variable instead of the investment horizon as the investment horizon determines the risk-free rate.

${ }^{11}$ Calculations are based on the historical monthly return distribution and are exemplarily calculated for an investment of $100 \%$ to the risky asset in the basic condition.

${ }^{12}$ Nevertheless, the endogeneity issue is addressed by correlating the residuals of the regression models on the investment amount and the investment horizon. Both correlations have a value of 0.00 , which indicates that there is no endogeneity problem.

${ }^{13}$ Regressions are checked for multicollinearity using variance inflation factors. The maximum variance inflation factor of any of the explanatory variables is 1.31 . This indicates that multicollinearity is not
} 


\section{Insert table 5 here.}

As the dependent variable is not normally distributed (due to the number of participants who invest $100 \%$ into the risky asset) Tobit and OLS regressions excluding these observations are run (but not reported here due to space constraints); the results do not differ qualitatively from the results described above in any meaningful way. Overall, the findings enable us to give an answer to our first research question: Investors do a sensible thing, they invest more into the risky asset when they are less risk averse and when they perceive the risk to be lower.

\section{Effects of the Risk-Return Profile Given on Risk Taking}

Framing should not matter: participants can and should choose the same risk-return profile for their portfolio across conditions by varying their respective allocations to the risky asset. However, participants change their percentage-allocations only slightly: they on average invest $59 \%$ into the risky asset in the de-levered condition, compared to $57 \%$ in the basic and $55 \%$ in the levered condition (see table 6 ) and only the difference between the allocation in the de-levered and the levered condition is significant $\left(t_{633}=\right.$ $2.24, p=0.03)$; results are comparable for median instead of mean allocations. Table 6 gives a descriptive overview of the chosen allocations by condition and self selected time horizon. While the allocation to the risky asset increases with the time horizon (compare Klos et al., 2005; Siebenmorgen and Weber, 2004), differences between conditions do not change significantly. ${ }^{14}$

\section{Insert table 6 here.}

An analysis of mean allocations shows that participants slightly (but not significantly) adjust their percentage allocations. Nevertheless, it might be that even these small adjustments between conditions lead to similar portfolios in terms of risk and return. Figure 5 shows the different risky assets given as well as the risk-return profiles chosen in a $\mu$ - $\sigma$-diagram, exemplarily for the five year horizon. ${ }^{15}$ The risky assets provided differ in the risk-return profile, but are approximately ${ }^{16}$ located on the same capital market line. It is therefore possible to end up with a similar risk-return profile between conditions by combining the risky asset with a certain fraction of the risk-free asset. If framing did

a problem.

${ }^{14}$ Differences between the levered and the de-levered condition are only marginally significant for the one year time horizon and not at all significant for the other time horizons; as time horizon is self selected, it might be that we find a selection bias in the data, e.g. that less risk averse participants choose longer time horizons and therefore allocate a higher fraction to the risky asset. We therefore later on control for risk attitude as well as other personal traits and demographics in a multivariate setting.

${ }^{15}$ Results look similar for the one year as well as the ten year time horizon.

${ }^{16}$ The assets are not exactly on the same line, as we constructed the levered and the de-levered by combining them with the historical and not a fixed risk-free rate (for further explanations, see section 3). However, changes are only marginal and the constructed portfolios differ by far stronger from each other than the difference with regard to the interest rates could explain. 
not matter, subjects would end up at the same point in the diagram by changing their percentage allocation dependent on the condition they face. The graph shows that the mean allocation in the de-levered condition of $56.3 \%$ for the five year time horizon results in an annual expected return of $5.2 \%$ and a volatility of $6.4 \%$. An investor desiring this could end up with the same portfolio by investing $40 \%$ to the risky asset in the basic condition or by investing $30 \%$ to the risky asset in the levered condition. The graph shows a different picture, however: the mean percentage allocations chosen by our participants ( $51.7 \%$ in the basic condition, $54.8 \%$ in the levered condition) result in economically and statistically meaningful differences between conditions in terms of both expected return and standard deviation. The comparatively small differences in percentage allocation to the risky fund between conditions are far from being sufficient to result in similar risk-return profiles for the portfolios. To put things into numbers, these allocations on average result in significantly different portfolio volatility of $6.4 \%$ for participants in the de-levered, $11.5 \%$ in the basic and $15.9 \%$ in the levered condition respectively ( $\mathrm{p}<$ 0.01 for all pairwise t-tests as well as for the bonferroni post-hoc pairwise comparison tests). In line with the findings of Benartzi and Thaler (2001), the risk of the chosen allocation increases significantly with the riskiness of the risky asset. Results for the mean \%-allocations suggest the existence of a severe framing effect.

\section{Insert figure 5 here.}

On an individual level, allocations to the risky assets are distributed over the whole possible range in each of the conditions. Comparing the distributions between conditions (see figure 6(a)), there is no evidence that similar mean allocations in the de-levered, the basic, and the levered market portfolio can be explained by extreme values or abnormal distribution in one ore more of the conditions. Figure 6(b) shows the distributions of volatilities ${ }^{17}$ that correspond to the chosen percentage allocations.

\section{Insert figure 6 here.}

Figure $6 \mathrm{~b}$ shows that the distribution of selected volatilities becomes broader if the provided risky asset is made riskier. In general, a broader distribution is sensible, as participants get a broader range of possible volatilites that can be chosen in the levered condition as for example compared to the de-levered condition.

Keeping this in mind, there should be more participants investing $100 \%$ into the risky asset in the de-levered condition than in the basic condition, as well as more in the basic condition than in the levered condition. However, $11 \%$ of participants invest $100 \%$ into the risky asset in the de-levered condition, compared to $9 \%$ in the basic and $11 \%$ in the levered condition. Looking at the chosen volatility the framing effect becomes even more obvious: In the de-levered condition $11 \%$ take the highest possible risk - resulting in a volatility of $11.4 \%$. In the basic condition $52 \%$ take on a volatility of $11.4 \%$ or higher and in the levered condition as much as $72 \%$ do so. Participants distribute their allocation

\footnotetext{
${ }^{17}$ The results stay the same if we plot return distributions.
} 
to the risky fund over the potential range independently of changes in the risk-return profile of the given risky asset.

A comparison of the cumulative distribution of the observed percentage allocations with a hypothetical distribution that would be consistent across our conditions gives further evidence for the strength of the framing effect: with the basic portfolio as the reference curve it is possible to calculate what the cumulative distribution should be in the de-levered or the levered conditions respectively if participants wanted to obtain the same final allocation on the capital market line, e.g. a participant investing $60 \%$ to the risky asset in the basic condition would need to invest around $90 \%$ in the de-levered condition and around $35 \%$ in the levered condition to get to the same risk-return profile in his portfolio. The difference between the hypothetical, "rational" distributions and the realized distributions is plotted in figure $7(\mathrm{a})$.

\section{Insert figure 7 here.}

The left part of figure 7(a) illustrates what the cummulative distribution functions (CDFs) of the de-levered and the levered conditions should look like if participants behaved in accordance with the observed behavior in the basic condition. The right part of figure 7(a) illustrates how the distribution of the chosen allocations in our experiment actually looks like: People do not change their percentage allocation to the risky fund if the asset gets more risky - and this is the case not only for high percentage allocations (which could be explained by a ceiling effect), but for the whole distribution of allocations. A Kolmogorov-Smirnov test shows that there are no measurable differences in distributions between conditions.

As an additional robustness check, figure 7(b) shows the CDFs for participants with a risk attitude between 1 and 4 . The maximum volatility that can be chosen ranges between $11.4 \%$ in the de-levered condition to $29 \%$ in the levered condition. Among the participants with a risk attitude between 1 and 4, three quarters have chosen a volatility below $11.4 \%$ and over $80 \%$ have allocated less than $75 \%$ to the risky asset). The graphs in figure 7(b) show that even participants with a low risk attitude between 1 and 4 (who are able to choose the same risk-return profile within all conditions) select similar allocations resulting in significantly different risk-return profiles. An example in numbers: a person with a risk attitude of 2 on average chooses a volatility of $4.5 \%$ (resulting from an allocation of $40 \%$ to the risky asset) in the de-levered condition, $7.5 \%$ in the basic condition ( $37 \%$ to the risky asset) and $10.9 \%$ in the levered condition (37\% to the risky asset).

The results hold in a multivariate OLS regression analysis with allocation as well as chosen volatility as a dependent variable. Table $7(1)$ shows that there is no significant change in percentage allocations induced by providing different risky assets. An even more precise measure of the framing effect may be obtained from a regression with chosen volatility as a dependent variable. If framing did not matter, the dummy variables for the de-levered and the levered conditions (the basic condition is omitted) should not have a significant influence; however, we find that both condition dummies (see table $7(2)$ ) significantly predict the chosen volatility. 
As a robustness check, results can be replicated in a sub-sample regression of participants with a risk attitude between 1 and 4 (table $7(3)$, the same sub-sample we used in figure $7(\mathrm{~b})$ ). Overall, an analysis on the individual level strengthens the evidence that participants do not base their allocation decision on the riskiness of the provided risky asset; the results of the multivariate analysis indicate that there are other objective and subjective variables which influence the allocation decision.

These main explanatory variables are risk attitude, investment horizon, and risk perception. Risk attitude is an exogenous variable and said to be a stable personality trait. It significantly predicts allocation as well as chosen volatility (see table 7). Risk perception, however, is likely to be influenced by the given risky asset. If we compare risk perception of the risky asset between conditions, we do not find any significant differences: participants on average reported a risk perception of 4.5 in the de-levered condition, of 4.6 in the baseline condition, and of 4.5 in the levered condition. This is in line with the framing effect - a risky asset is perceived risky independently of changes in riskiness (i.e. volatility).

We additionally asked participants about the portfolio risk perception of their chosen allocation instead of the risky asset itself; results support former findings: portfolio risk perception of participants who take on the same percentage allocation (e.g. allocating between $45 \%$ and $55 \%$ to the risky asset) are not significantly different: 3.4 in the delevered condition, 3.5 in the baseline condition, and 3.5 in the levered condition. However, the portfolio risk perceptions of participants who choose the same volatility, e.g. between 0.04 and 0.08 (and therefore face the same objective risk level), differ between conditions with an average of 3.34 in the de-levered condition, 3.14 in the baseline condition and 2.82 in the levered condition. The difference is significant for the pairwise t-tests between the levered and the de-levered condition and marginally significant for the difference between the de-levered and the baseline condition; the bonferroni post-hoc pairwise comparison test shows a significant difference between the levered and the de-levered condition; to put it simple: portfolio risk perception depends on the percentage allocated to the risky asset and not on the objective riskiness/volatility.

\section{Insert table 7 here.}

Overall, investors indeed do something sensible: they base their risk taking decision on their risk preferences and their time horizon. However, the decision variable "risk" seems to be driven by the question "what absolute amount do I wish to invest riskily" instead of "what risk level (how much volatility) do I wish to take". In the remainder of this section, we will analyze the robustness of the observed framing effect by testing two variations. 1. We find an abundance of evidence in the literature that a higher degree of financial literacy improves financial decision making; therefore, the interaction of financial knowledge and framing will be explored (Campbell, 2006; Calvet et al., 2007). 2. The framing of riskiness can be induced subjectively and objectively. For the objective variation, an additional condition with a dominating asset is included so we can see whether participants adjust their allocation if differences in risk-return profiles become 
more obvious. For the subjective variation we include asset names for the basic and the dominating asset to determine whether the framing effect interacts with more subjective information.

\section{Financial Literacy and Asset Allocation}

To test for the framing effect for different degrees of financial knowledge, the sample is split into two sub-samples relative to the median financial literacy score, resulting in sub-samples with relatively high and low financial literacy. Participants with a higher financial literacy in general tend to invest a higher fraction into the risky asset, with a mean allocation of $60.34 \%$ versus $53.36 \%$ for participants with lower financial literacy. This is not surprising as financial literacy is significantly positive correlated with risk attitude $(\rho=0.30, p<0.00)$. Table 8 reports the chosen allocation for the different conditions by financial literacy groups: participants with high financial literacy significantly adjust their allocation in the de-levered condition. The bonferroni post-hoc pairwise comparison test shows a significant difference between the levered and the de-levered condition as well as between the de-levered and basic condition on the $5 \%$ significance level. Nevertheless the resulting portfolios of the high financial literacy group still differ economically: a mean allocation of $65 \%$ in the de-levered condition results in a annual volatility of $7.4 \%$, whereas the $58 \%$ invested in the basic and the levered condition result in an annual volatility of $11.8 \%$ and $17.1 \%$ respectively. In the low financial literacy group, a bonferroni post-hoc pairwise comparison test shows no differences between conditions at all.

\section{Insert table 8 here.}

The uni-variate results are confirmed in an OLS regression with allocation as the dependent variable: the dummy for the de-levered condition (the basic condition is omitted) is positive as well as significant in the high financial literacy group (see 9 (2)) and not significant in the low financial literacy group $(9(1))$. However, an OLS regression model with chosen volatility as a dependent variable ${ }^{18}$ shows that the changes in allocation are still far from resulting in similar portfolios in terms of volatility. The framing effect still persists in both financial literacy groups (compare table 9 (3) and (4)). The results are similar if we compare participants with stock market experience to participants without stock market experience (correlation to financial literacy 0.20 ) or participants working in the financial industry to those not working in the financial industry (correlation to financial literacy 0.31).

\section{Insert table 9 here.}

An additional effect we observe in the regressions is that the influence of investment horizon is only significant in the high financial literacy group and that the effect of risk perception seems to be stronger in the low financial literacy group, indicating that people with higher financial literacy at least to a certain extent take into account objective risk measures. If we include the volatility and the annual expected return into the regression

\footnotetext{
${ }^{18}$ Again, results do not differ using a Tobit model.
} 
(comparable to table 5, not reported) the results support this idea: standard deviation of the provided risky asset, investment amount and investment horizon significantly predict asset allocation in the high financial literacy group, while only standard deviation has a significant influence in the low financial literacy group.

\section{Objective Persistence of the Framing Effect: Dominating Asset}

One reason for the overall small adjustment might be that differences in risk-return profiles are not obvious enough. We therefore analyze differences in allocations between the basic asset and a dominating asset, which offers a higher return combined with a lower risk. As an asset with a higher Sharpe-ratio is now provided, investors should invest significantly more into that dominating asset compared to the basic asset. We find an adjustment in the data: participants on average invest $57 \%$ into the risky asset in the basic condition and $62 \%$ in the dominating condition. This difference is significant $\left(t_{642}=2.14, p=0.03\right){ }^{19}$

\section{Insert table 11 here.}

Results of an OLS regression model with allocation as a dependent variable, ${ }^{20}$ show that the significant adjustment for the full sample is driven by the high financial literacy group (see table 11(2)), whereas no differences in allocations between the basic and the dominating condition can be found in the low financial literacy group (see table 11(1)). We do not analyze differences in volatility as these can be expected by construction: the dominating asset has a lower volatility and a higher return, thus making it sensible for participants to take on a higher or a lower volatility when compared to the basic asset. Differences in demographic variables between the two sub-sample regressions can be explained by the differences in participants between the two groups: in the high (low) financial literacy group $92 \%(82 \%)$ are male, $88 \%(72 \%)$ are invested into stocks and the mean risk attitude is 4.59 (3.83). Investors with high financial literacy overall seem to take large differences in risk-return profiles into account, while participants with low financial literacy don't seem to do so on the same scale.

\section{Subjective Persistence of Framing Effect}

The information about the risky asset in the main conditions and the dominating asset condition was intentionally kept vague ("risky fund investing into capital markets") as we wanted subjects to focus on the return distribution. In two further conditions, an additional information about the risky asset was included - the asset name. The DAX condition has the exact same return distribution as the basic asset while the World Portfolio condition has the same return distribution as the dominating asset. In the DAX specification, participants are told that the risky asset is a fund replicating the German stock index (DAX), which represents the 30 largest (based on market capitalization) and most liquid German companies. In the World Portfolio specification, participants are informed that the risky asset is a fund replicating the performance of stocks (60\%), bonds (25\%) and commodities (15\%) from all over the world (Jacobs et al., 2010). Consistent

\footnotetext{
${ }^{19}$ Results are similar if we compare allocations to the levered or the de-levered asset with those to the dominating asset.

${ }^{20}$ Again, results do not change if we use a Tobit regression.
} 
with the literature (e.g. E. Weber et al. (2005)), participants take on higher risk if asset names are provided (see table 10): participants on average invest $57 \%$ into the basic asset as compared to $61 \%$ in the DAX asset and $62 \%$ in the dominating asset as opposed to $65 \%$ to the World Portfolio asset, however, the effect is only marginally significant for the difference between the basic asset and the DAX $(p=0.09)$. Even if the influence on risk taking itself is not significant, results show a significant change in risk perception if asset names are included: reported risk perception in the basic condition is 4.63 in basic asset as compared to 4.40 in the DAX asset (t-test, $\mathrm{p}=0.01$ ) and 4.59 in the dominating asset as opposed to 4.42 in World Portfolio asset (t-test, $\mathrm{p}=0.07$ ). Interestingly, an objective variation in risk (different volatilities) does not change a subjective measure like risk perception while a subjective variation in the sense of information (asset names) does. One reason might be that the inclusion of asset names increases how familiar investors feel with their investment; while the absolute level of risk taking increases for both named asset, the relative difference between the dominating asset and the basic asset is equal to the relative difference between the two named assets. The objective risk adjustment is hence not influenced by the provision of asset names and results do not change if we include control variables in an OLS regression (not reported). Asset names seem to have an influence on the risk, but not on the riskiness. This finding also holds if we analyze our two sub-samples: participants with low financial literacy increase their risk taking by 4 percentage points on average for the DAX (61\% instead of 57\%) and the World Portfolio (again $61 \%$ instead of 57\%) if asset names are included, but there are still no differences between the two assets. Participants with high financial literacy increase their risk taking by 3 percentage points for the DAX (61\% instead of 58\%) and the World Portfolio (68\% instead of $65 \%$ ) if asset names are included, and the difference between the two assets stays significant $\left(t_{(346)}=2.93, \mathrm{p}<0.01\right)$. The results suggest that the inclusion of subjective information (as the asset names) does not influence the behavior in a way that investors are able to judge differences in riskiness between the risky assets. They instead seem to generally increase risk taking, which is likely to be induced by a lower risk perception.

\section{Insert table 10 here.}

\section{Discussion}

In the current paper we analyze two research questions which are highly relevant for private investors and have great policy implications. The good outcome of our analysis is: investors behave more rational than they are often said to; they base their decision on risk preferences like risk attitude and risk perception and, at least those with a high financial literacy, behave in accordance to personal circumstances like their invested amount or the planned investment horizon.

Nevertheless, we also find a strong framing effect when it comes to the overall portfolio risk: On average participants do not change their fraction invested risky as opposed to risk-free when the risk-return profile of the assets given changes. Our conclusion is that investors seem to have two mental accounts - one for their risk-free investment, 
another one for their risky investment - with a fixed percentage allocation to each of the two accounts in mind and disregarding the overall portfolio volatility. An adjustment seems to be non-existent for participants with low financial literacy; people with a higher financial literacy adjust when differences between risk-return profiles of given assets get more obvious, but their adjustment is still insufficient.

It does not seem that these findings can be explained by a lack in experimental validity; our sample size is by far larger than in comparable experiments and our participants are assigned randomly to our different conditions. As a consequence, characteristics across conditions do hardly differ. In the following we discuss different explanations for this behavior.

One explanation might be that investors use decision heuristics induced by the advisory process in banks. Generally, advisers elicit the risk preferences of their customers by asking them to state them on a scale (e.g. on a one to five scale ranging from 'not willing to accept any risk' to 'willing to accept a substantial risk in order to have the chance to receive higher returns'). This information is then used to recommend certain investment products to the customer. Some banks also use model portfolios in their advisory process where the percentage allocated risky differs for different risk attitudes. This percentage rate is not directly related to the overall volatility of the portfolio that is constructed for the investor. In this special case, customers are taught that the riskiness of their portfolio is determined by the amount they invest into risky assets, but neither their riskiness nor the overall portfolio volatility are taken into account in the first step. Furthermore this process reduces complexity for the investor; it is less complicated to decide how much to invest risk-free than to think about an overall portfolio volatility. In future research, different anchors like a maximum loss or percentage allocations suggested by investment advisers could be compared.

Another perspective on the observed behavior is to ask whether it indeed could be rational and is not induced by framing or anchoring - it just has the same consequences as one would expect from the manipulation. It might be that the private investor has another risk concept in mind. Riskiness for him is not risk measured by risk indicators, but in a first step everything which is not invested safely. When it comes to asset allocation people could think about the amount they need for sure after the investment period and this is the amount they allocate to the risk-free asset. Even if it is not realistic that participants lose all the money invested risky, they have only ambiguous statistics to rely on. We know that past returns work as an indicator, but we cannot use hindsight as foresight as it were a predictor (Taleb et al., 2009). The idea is supported by our findings that participants perceive the same percentage allocation to the safe (or the risky asset) across conditions as similarly risky - even if the objective risk in terms of volatility differs significantly. Additionally, we asked participants about the minimum amount they will need after the investment horizon (not reported in the results section), and this amount significantly predicts asset allocation decisions: when a small minimum amount is needed, participants invest a lot risky and still achieve their minimum for sure. A medium amount leads to a small allocation to the risky asset such that they still achieve the minimum amount for sure. If a large minimum amount is needed, investors gamble as this is the only way to achieve their minimum amount. With this in mind, 
it might be that we need a two-stage approach to elicit participants' risk preferences - first elicit the investment they need to have safe and secondly help them to allocate their risky invested money also taking the safe money into account. Investors may be more attentive to think about the "risky account" and realize differences between risky options once they are sure that the amount they need safe has been set aside. This is a question we want to investigate in future research. In line with that, it would be interesting whether these results hold for different investment purposes; it may be that investors use the mechanisms described above differently if they invest for retirement as opposed to future consumption they do not depend on.

Apart from their theoretical importance, our findings have important policy implications; they contribute to the current debate on the communication of investment risks to investors and on the measurement of investors' risk attitude. With the heuristics we describe, the choice of the risk-return profile used for the elicitation of risk preferences is crucial. A riskier asset will lead to a lower measured risk aversion. We know from the literature that standard deviation is a concept hardly understood by private investors, even quantitative analyst seem to fail by handling calculations correctly (Taleb et al., 2009). Even the use of a risk simulation - which does not state the volatility, but lets investors experience it - does not lead to major attention towards different risk levels. New EU regulations such as the European Undertakings for Collective Investment in Transferable Securities Directives (UCITS) and the Key Investor Information Document (KIID), request that mutual funds must be described in detail; together with other information, this document presents the volatility of returns as a simplified risk indicator with seven categories, which are calculated based on the historical volatility. In order to choose from these seven categories, investors would first have to find their personal category. Our findings show that the elicitation of a risk category depends crucially on the assets chosen for the elicitation process. If a riskier asset is chosen, the average investor will be categorized as more risk-seeking and funds from a higher category will be recommended. The measurement of an individual's risk preference has to be standardized in order to avoid conscious and unconscious manipulations resulting from the choice of different reference assets. Further research needs to investigate whether the indicator itself can help to better incorporate and understand information about the riskiness of an asset.

\section{References}

Anderson, B. F., Settle, J. W., 1996. The influence of portfolio characteristics and investment period on investment choice. Journal of Economic Psychology 17 (3), 343-358.

Baucells, M., Villasís, A., 2010. Stability of risk preferences and the reflection effect of prospect theory. Theory and Decision 68 (1), 193-211.

Benartzi, S., Thaler, R. H., 1995. Myopic loss aversion and the equity premium puzzle. Quarterly Journal of Economics 110 (1), 73-92.

Benartzi, S., Thaler, R. H., 2001. Naive diversification strategies in defined contribution saving plans. The American Economic Review 91 (1), 79-98. 
Börsch-Supan, A., Coppola, M., Essig, L., Eymann, A., Schunk, D., 2009. The German SAVE study - design and results.

Calvet, L., Campbell, J., Sodini, P., 2007. Down or out: Assessing the welfare costs of household investment mistakes. The Journal of Political Economy 115 (5), 707-747.

Campbell, J. Y., 2006. Household finance. Journal of Finance 61 (4), 1553-1604.

Canner, N., Mankiw, N. G., Weil, D. N., 1997. An asset allocation puzzle. American Economic Review 87 (1), 181-191.

Croson, R., Gneezy, U., 2009. Gender differences in preferences. Journal of Economic Literature 47 (2), 448-474.

DESTATIS, 2006. Nettoeinkommen und Zahl der Haushalte nach Haushaltsgruppen. Tech. rep.

DESTATIS, 2010. Statistical yearbook 2010. Tech. rep.

Diacon, S., Hasseldine, J., 2007. Framing effects and risk perception: The effect of prior performance presentation format on investment fund choice. Journal of Economic Psychology 28 (1), 31-52.

Dorn, D., Huberman, G., 2005. Talk and action: What individual investors say and what they do. Review of Finance 9 (4), 437-481.

Dorn, D., Huberman, G., 2010. Preferred risk habitat of individual investors. Journal of Financial Economics 97 (1), 155-173.

European Parliament, European Council, 2004. Markets in financial instruments directive (2004/39/EC).

European Parliament, European Council, 2006. Amending directive 2004/39/EC on markets in financial instruments $(2006 / 31 /$ EC).

European Parliament, European Council, 2009. Undertakings for collective investment in transferable securities (UCITS) directive (2009/65/EC).

Frijns, B., Koellen, E., Lehnert, T., 2008. On the determinants of portfolio choice. Journal of Economic Behavior \& Organization 66 (2), 373-386.

Gneezy, U., Potters, J., 1997. An experiment on risk taking and evaluation periods. Quarterly Journal of Economics 112 (2), 631-645.

Haisley, E. C., Kaufmann, C., Weber, M., 2011. The role of experience sampling and graphical displays on one's investment risk appetite and comprehension. Working Paper.

Huberman, G., Jiang, W., 2004. Offering vs. choice in 401(k) plans: Equity exposure and number of funds. Working Paper. 
Jacobs, H., Müller, S., Weber, M., 2010. How should private investors diversify? An empirical evaluation of alternative asset allocation policies to construct a 'world market portfolio'. Working Paper.

Jia, J., Dyer, J. S., Butler, J. C., 1999. Measures of perceived risk. Management Science $45(4), 519-532$.

Kapteyn, A., Teppa, F., 2009. Subjective measures of risk aversion, fixed costs, and portfolio choice. Working Paper.

Kaustia, M., Alho, E., Puttonen, V., 2008. How much does expertise reduce behavioral biases? The case of anchoring effects in stock return estimates. Financial Management 37 (3), 391-411.

Klos, A., 2011. Central tendency error and self-reported risk attitudes. Working Paper.

Klos, A., Weber, E. U., Weber, M., 2005. Investment decisions and time horizon: Risk perception and risk behavior in repeated gambles. Management Science 51 (12), 17771790.

Kroll, Y., Levy, H., Rapoport, A., 1988a. Experimental tests of the mean-variance model for portfolio selection. Organizational Behavior and Human Decision Processes 42 (3), $388-410$.

Kroll, Y., Levy, H., Rapoport, A., 1988b. Experimental tests of the separation theorem and the capital asset pricing model. American Economic Review 78 (3), 500-519.

Lintner, J., 1965. The valuation of risk assets and the selection of risky investments in stock portfolios and capital budgets. The Review of Economics and Statistics 47 (1), $13-37$.

Markowitz, H., 1952. Portfolio selection. The Journal of Finance 7 (1), 77-91.

Mehra, R., Prescott, E. C., 1985. The equity premium: A puzzle. Journal of Monetary Economics 15 (2), 145-161.

Merton, R. C., 1969. Lifetime portfolio selection under uncertainty: The continuous-time case. Review of Economics and Statistics 51 (3), 247-257.

Müller, S., Weber, M., 2010. Financial literacy and mutual fund investments: Who buys actively managed funds? Schmalenbach Business Review (SBR) 62 (2), 126-153.

Mossin, J., 1966. Equilibrium in a capital asset market. Econometrica 34 (4), 768-783.

Nosic, A., Weber, M., 2010. How riskily do I invest? The role of risk attitudes, risk perceptions, and overconfidence. Decision Analysis 7 (3), 282-301.

Nosic, A., Weber, M., Glaser, M., 2011. Opening the black box: From an individual bias to portfolio performance. Working Paper. 
Sahm, C., 2007. How much does risk tolerance change? Working Paper.

Sarin, R. K., Weber, M., 1993. Risk-value models. European Journal of Operational Research 70 (2), 135-149.

Sharpe, W. F., 1964. Capital asset prices: A theory of market equilibrium under conditions of risk. The Journal of Finance 19 (3), 425-442.

Siebenmorgen, N., Weber, M., 2004. The influence of different investment horizons on risk behavior. Journal of Behavioral Finance 5 (2), 75-90.

Sitkin, S. B., Pablo, A. L., 1992. Reconceptualizing the determinants of risk behavior. Academy of Management Review 17 (1), 9-38.

Sitkin, S. B., Weingart, L. R., 1995. Determinants of risky decision-making behavior: A test of the mediating role of risk perceptions and propensity. The Academy of Management Journal 38 (6), 1573-1592.

Taleb, N. N., Goldstein, D. G., Spitznagel, M. W., 2009. The six mistakes executives make in risk management. Havard Business Review, 1-5.

Thaler, R. H., 1999. Mental accounting matters. Journal of Behavioral Decision Making $12(3), 183-206$.

Tobin, J., 1958. Liquidity preference as behavior towards risk. The Review of Economic Studies 25 (2), 65-86.

Treynor, J. L., 1962. Toward a theory of market value of risky assets (unpublished manuscript).

Tversky, A., Kahneman, D., 1974. Judgment under uncertainty: Heuristics and biases. Science 185 (4157), 1124-1131.

Tversky, A., Kahneman, D., 1981. The framing of decisions and the psychology of choice. Science, New Series 211 (4481), 453-458.

van Rooij, M., Lusardi, A., Alessie, R., 2011. Financial literacy and stock market participation. Journal of Financial Economics 101 (2), 449-472.

Vlaev, I., Chater, N., Stewart, N., 2009. Dimensionality of risk perception: Factors affecting consumer understanding and evaluation of financial risk. Journal of Behavioral Finance 10 (3), 158-181.

Weber, E. U., Blais, A.-R., Betz, N. E., 2002. A domain-specific risk-attitude scale: Measuring risk perceptions and risk behaviors. Journal of Behavioral Decision Making $15(4), 263-290$.

Weber, E. U., Milliman, R. A., 1997. Perceived risk attitudes: Relating risk perception to risky choice. Management Science 43 (2), 123-144. 
Weber, E. U., Siebenmorgen, N., Weber, M., 2005. Communicating asset risk: How name recognition and the format of historic volatility information affect risk perception and investment decisions. Risk Analysis: An International Journal 25 (3), 597-609. 
Table 1: Interest rates for different investment horizons

\begin{tabular}{lc}
\hline Investment horizon & Return \\
\hline One year & $1.0 \%$ \\
Five years & $2.5 \%$ \\
Ten years & $3.4 \%$ \\
\hline
\end{tabular}

This table reports the interest rates for different investment horizons.

The respective investment horizon can be chosen by the participants. 
Table 2: Return and standard deviation of the risky assets

\begin{tabular}{lcc}
\hline Main Conditions & Return & Risk (st.d.) \\
\hline De-levered asset & $7.4 \%$ & $11.4 \%$ \\
Basic asset & $8.9 \%$ & $20.0 \%$ \\
Levered market portfolio & $11.6 \%$ & $29.1 \%$ \\
\hline Ancillary conditions & Return & Risk (st.d.) \\
\hline Dominating asset & $11.6 \%$ & $11.4 \%$ \\
World portfolio (named) & $11.6 \%$ & $11.4 \%$ \\
DAX (named) & $8.9 \%$ & $20.0 \%$ \\
\hline
\end{tabular}

This table reports characteristics of the different risky assets. The three main conditions are based on returns of the German stock index DAX. The ancillary conditions include dominating and named assets. Conditions are randomly assigned. 
Table 3: Descriptive Statistics

(a) Income

\begin{tabular}{lrc}
\hline Income & $\mathbf{N}$ & German average \\
\hline less than $€ 12,000$ & 179 & $€ 33,700$ \\
$€ 12,000$ to $€ 30,000$ & 410 & \\
$€ 30,000$ to $€ 50,000$ & 648 & \\
$€ 50,000$ to $€ 100,000$ & 402 & \\
more than $€ 100,000$ & 125 & \\
no answer & 194 & \\
N & 1958 & \\
\hline
\end{tabular}

(b) Education

\begin{tabular}{lrrr}
\hline Education & N & Percentage sample & Percentage Germany \\
\hline Still in school & 19 & $0.97 \%$ & $3.25 \%$ \\
Hauptschule & 107 & $5.46 \%$ & $38.43 \%$ \\
Realschule & 398 & $20.33 \%$ & $21.42 \%$ \\
Gymnasium & 424 & $21.65 \%$ & $11.69 \%$ \\
University & 864 & $44.13 \%$ & $12.50 \%$ \\
Ph.D. & 146 & $7.46 \%$ & $1.07 \%$ \\
No response/Other & 0 & $0.00 \%$ & $11.64 \%$ \\
N & 1958 & $100.00 \%$ & $100.00 \%$ \\
\hline
\end{tabular}

(c) Other variables

\begin{tabular}{lrrrrc}
\hline Variable & Mean & St.D. & Min. & Max. & German average \\
\hline Risk attitude & 4.23 & 1.37 & 1 & 7 & 2.24 \\
Financial literacy & 8.19 & 1.16 & 0 & 9 & - \\
Age & 42.17 & 16.99 & 11 & 109 & 55.44 \\
Male gender & 0.87 & 0.33 & 0 & 1 & 0.49 \\
Stock market participation & 0.81 & 0.39 & 0 & 1 & 0.25 \\
Financial professional & 0.31 & 0.46 & 0 & 1 & - \\
N & 1,958 & & & & \\
\hline
\end{tabular}

Table 3(a) shows the number of participants in a certain income range. The German average is taken from DESTATIS (2006). Table 3(b) reports the education level of participants. There is no equivalent school in the English system for some German school types. Hauptschule and Realschule enable to begin an apprenticeship; Realschule makes it easier to switch to Gymnasium later. Gymnasium directly enables to attend a university. The average German percentages are calculated from DESTATIS (2010). Table 3(c) reports summary statistics for other variables. The German averages for risk attitude (measured on a 1-10 scale), age, and stock market participation are taken form the German SAVE study (Börsch-Supan et al., 2009); the German average for gender is taken from DESTATIS (2010). 
Table 4: Self-selected decision context

(a) Investment amount

\begin{tabular}{lr}
\hline Investment amount & $\mathrm{N}$ \\
\hline$€ 5,000$ & 771 \\
$€ 50,000$ & 734 \\
$€ 100,000$ & 453 \\
& 1,958 \\
\hline
\end{tabular}

(b) Investment horizon

\begin{tabular}{lr}
\hline Investment horizon & $\mathrm{N}$ \\
\hline 1 year & 521 \\
5 years & 939 \\
10 years & 498 \\
& 1,958 \\
\hline
\end{tabular}

Table 4(a) reports the number of participants who choose a certain investment amount and table 4(b) reports the number of participants who choose a certain investment horizon. 
Table 5: Allocation to the risky asset

(1)

allocation to the risky asset

\begin{tabular}{lc}
\hline Risk Attitude & $0.074^{* * *}$ \\
& $(0.004)$ \\
Perceived Risk of the asset provided & $-0.042^{* * *}$ \\
& $(0.004)$ \\
Investment Horizon & $0.007^{* * *}$ \\
& $(0.002)$ \\
$\log$ (Investment Amount) & $-0.013^{* * *}$ \\
& $(0.004)$ \\
Stock market participation & -0.009 \\
& $(0.014)$ \\
Male Gender & $0.027^{*}$ \\
Age & $(0.015)$ \\
& -0.000 \\
Education & $(0.000)$ \\
annually return of the portfolio provided & 0.001 \\
annually std of the portfolio provided & $(0.005)$ \\
Constant & $0.756^{* *}$ \\
& $(0.298)$ \\
Observations & $-0.379^{* * *}$ \\
\hline
\end{tabular}

This table reports results of an OLS regression explaining allocation with the stated risk attitude. Perceived risk, investment amount, and investment horizon also influence the allocation to the risky asset in the predicted way. Standard errors are in parentheses. ${ }^{*}$ indicates significance at the $10 \%$-level, ${ }^{* *}$ at the $5 \%$-level, and ${ }^{* * *}$ at the $1 \%$-level. 
Table 6: Percentage allocations to the risky assets

\begin{tabular}{lllllllllll}
\hline & \multicolumn{3}{l}{ De-levered asset } & \multicolumn{3}{c}{ Basic asset } & \multicolumn{3}{c}{ Levered asset } \\
\hline & Mean & Median & $\mathrm{N}$ & Mean & Median & $\mathrm{N}$ & Mean & Median & $\mathrm{N}$ \\
All horizons & 0.593 & 0.6 & 323 & 0.574 & 0.6 & 331 & 0.547 & 0.5 & 312 \\
One year & 0.55 & 0.55 & 72 & 0.599 & 0.6 & 79 & 0.48 & 0.5 & 99 \\
Five years & 0.563 & 0.545 & 160 & 0.517 & 0.5 & 164 & 0.548 & 0.5 & 137 \\
Ten years & 0.679 & 0.73 & 91 & 0.658 & 0.625 & 88 & 0.633 & 0.63 & 76 \\
\hline $\begin{array}{l}\text { This table reports the resulting mean and median allocations to the risky fund divided by the total } \\
\text { endowment. Results are reported for the three main conditions across and between self-selected time } \\
\text { horizons. These numbers are descriptive, see table 7 for regressions controlling for other influences. }\end{array}$
\end{tabular}


Table 7: Chosen allocation and volatility

\begin{tabular}{lccc}
\hline & $(1)$ & $(2)$ & $(3)$ \\
& allocation & volatility & vola, risk-attitude 1-4 \\
\hline De-levered asset & 0.013 & $-0.048^{* * *}$ & $-0.041^{* * *}$ \\
& $(0.018)$ & $(0.004)$ & $(0.005)$ \\
Levered asset & -0.020 & $0.046^{* * *}$ & $0.041^{* * *}$ \\
& $(0.018)$ & $(0.004)$ & $(0.005)$ \\
Risk attitude & $0.069^{* * *}$ & $0.014^{* * *}$ & $0.014^{* * *}$ \\
Perc. risk (asset provided) & $(0.006)$ & $(0.001)$ & $(0.003)$ \\
& $-0.034^{* * *}$ & $-0.007^{* * *}$ & $-0.008^{* * *}$ \\
Investment horizon & $(0.006)$ & $(0.001)$ & $(0.002)$ \\
log(Investment amount) & $0.005^{* *}$ & $0.001^{* *}$ & 0.001 \\
& $(0.002)$ & $(0.001)$ & $(0.001)$ \\
Stock market participation & -0.008 & $-0.003^{*}$ & -0.003 \\
& $(0.006)$ & $(0.001)$ & $(0.002)$ \\
Male gender & 0.001 & -0.000 & 0.003 \\
Age & $(0.020)$ & $(0.004)$ & $(0.005)$ \\
Education & 0.030 & $0.009^{*}$ & $0.009^{*}$ \\
Constant & $(0.022)$ & $(0.005)$ & $(0.005)$ \\
& -0.000 & -0.000 & $-0.000^{*}$ \\
Odjusted $R^{2}$ & $(0.000)$ & $(0.000)$ & $(0.000)$ \\
& 0.002 & -0.001 & -0.001 \\
& $(0.006)$ & $(0.001)$ & $(0.002)$ \\
& $0.475^{* * *}$ & $0.106^{* * *}$ & $0.114^{* * *}$ \\
& $(0.075)$ & $(0.016)$ & $(0.022)$ \\
\hline & 966 & 966 & 529 \\
& 0.222 & 0.451 & 0.384 \\
\hline & & & \\
& & & \\
& & &
\end{tabular}

This table reports OLS regressions analyzing differences between conditions. The basic condition is omitted in all three regressions. The dummies for the de-levered and the levered asset show the respective difference to the basic asset. Regression (1) analyzes the effects on final allocations to the risky fund measured as a percentage of the initial endowment as dependent variable; (2) reports the effects on chosen volatility. In (3) the same regression as in (2) is performed for a sub-sample of participants with a risk attitude between 1 and 4 (on a 1-7 scale, where a higher number indicates a lower risk aversion). Standard errors are in parentheses. ${ }^{*}$ indicates significance at the $10 \%$-level, ${ }^{* *}$ at the $5 \%$-level, and ${ }^{* * *}$ at the $1 \%$-level. 
Table 8: Percentage allocations to the risky assets

\begin{tabular}{lllllllllll}
\hline & \multicolumn{3}{l}{ De-levered asset } & \multicolumn{3}{c}{ Basic asset } & \multicolumn{4}{c}{ Levered asset } \\
\hline & Mean & Median & $\mathrm{N}$ & Mean & Median & $\mathrm{N}$ & Mean & Median & $\mathrm{N}$ \\
Full sample & 0.593 & 0.6 & 323 & 0.574 & 0.6 & 331 & 0.547 & 0.5 & 312 \\
Low Fin. Lit. & 0.524 & 0.5 & 149 & 0.568 & 0.6 & 155 & 0.516 & 0.5 & 154 \\
High Fin. Lit. & 0.651 & 0.675 & 174 & 0.579 & 0.57 & 176 & 0.578 & 0.6 & 158
\end{tabular}

This table reports the mean and median allocations to the risky fund divided by the total endowment. Results are reported for the three main conditions across and between financial literacy groups. High (low) financial literacy refers to the group of participants with a financial literacy above (below) the median financial literacy score in the whole sample. These numbers are descriptive, see table 9 for regressions controlling for other influences. 
Table 9: Chosen allocation and volatility for different financial literacy groups

(1) (2) (3) (4)

alloc. low FL alloc. high FL vola low FL vola high FL

\begin{tabular}{lcccc}
\hline De-levered asset & -0.031 & $0.054^{* *}$ & $-0.051^{* * *}$ & $-0.045^{* * *}$ \\
& $(0.025)$ & $(0.024)$ & $(0.006)$ & $(0.005)$ \\
Levered asset & -0.031 & -0.009 & $0.041^{* * *}$ & $0.051^{* * *}$ \\
& $(0.025)$ & $(0.025)$ & $(0.006)$ & $(0.005)$ \\
Risk attitude & $0.073^{* * *}$ & $0.063^{* * *}$ & $0.015^{* * *}$ & $0.013^{* * *}$ \\
& $(0.008)$ & $(0.009)$ & $(0.002)$ & $(0.002)$ \\
Perc. risk (asset provided) & $-0.047^{* * *}$ & $-0.020^{* *}$ & $-0.009^{* * *}$ & $-0.005^{* *}$ \\
& $(0.009)$ & $(0.009)$ & $(0.002)$ & $(0.002)$ \\
Investment horizon & 0.001 & $0.010^{* * *}$ & 0.000 & $0.002^{* * *}$ \\
& $(0.003)$ & $(0.003)$ & $(0.001)$ & $(0.001)$ \\
log(Investment amount) & -0.002 & -0.014 & -0.002 & -0.003 \\
& $(0.009)$ & $(0.009)$ & $(0.002)$ & $(0.002)$ \\
Stock market participation & -0.006 & 0.008 & -0.001 & 0.002 \\
& $(0.025)$ & $(0.032)$ & $(0.006)$ & $(0.007)$ \\
Male gender & 0.031 & 0.032 & 0.009 & 0.009 \\
Age & $(0.026)$ & $(0.038)$ & $(0.006)$ & $(0.008)$ \\
& -0.001 & -0.000 & -0.000 & -0.000 \\
Education & $(0.001)$ & $(0.001)$ & $(0.000)$ & $(0.000)$ \\
Constant & -0.005 & 0.011 & -0.002 & 0.001 \\
& $(0.009)$ & $(0.010)$ & $(0.002)$ & $(0.002)$ \\
\hline Observations & $0.543^{* * *}$ & $0.394^{* * *}$ & $0.122^{* * *}$ & $0.085^{* * *}$ \\
Adjusted $R^{2}$ & $(0.103)$ & $(0.112)$ & $(0.023)$ & $(0.025)$ \\
\hline This & 458 & 508 & 458 & 508 \\
& 0.252 & 0.178 & 0.461 & 0.436 \\
\hline
\end{tabular}

This table reports OLS regressions of the chosen allocation and chosen volatility for different financial literacy groups. The basic condition is omitted in all three regressions. The dummies for the de-levered and the levered asset show the respective difference to the basic asset. Regression (1) analyzes the effects on final allocations to the risky fund in percent for the low financial literacy group (participants with a financial literacy score below the median); (2) reports the effects for the high financial literacy group (participants with a financial literacy score above the median). (3) analyzes the effects on chosen volatility for the same sub-sample as in (1), and (4) analyzes the effects on chosen volatility for the same sub-sample as in (2). Standard errors are in parentheses. ${ }^{*}$ indicates significance at the $10 \%$-level, ${ }^{* *}$ at the $5 \%$-level, and ${ }^{* * *}$ at the $1 \%$-level. 
Table 10: Allocations to the basic and the dominating asset (non-named and named)

\begin{tabular}{|c|c|c|c|c|c|c|c|c|}
\hline & \multicolumn{2}{|l|}{ Basic } & \multicolumn{2}{|c|}{ Dominating } & \multicolumn{2}{|c|}{ Dax (named) } & \multicolumn{2}{|c|}{ Dominating (named) } \\
\hline & Mean & $\mathrm{N}$ & Mean & $\mathrm{N}$ & Mean & $\mathrm{N}$ & Mean & $\mathrm{N}$ \\
\hline All horizons & 0.574 & 331 & 0.617 & 313 & 0.607 & 321 & 0.645 & 358 \\
\hline One year & 0.599 & 79 & 0.523 & 76 & 0.585 & 92 & 0.583 & 103 \\
\hline Five years & 0.517 & 164 & 0.602 & 159 & 0.577 & 144 & 0.638 & 175 \\
\hline Ten years & 0.658 & 88 & 0.739 & 78 & 0.68 & 85 & 0.743 & 80 \\
\hline
\end{tabular}


Table 11: Chosen allocation for basic and dominating asset

alloc. low FL alloc. high FL alloc. low FL alloc high FL

named

named

\begin{tabular}{lcccc}
\hline Dominating asset & 0.008 & $0.054^{* *}$ & & \\
& $(0.026)$ & $(0.023)$ & & \\
Dom. asset named & & & 0.022 & $0.072^{* * *}$ \\
& & & $(0.024)$ & $(0.023)$ \\
Risk attitude & $0.092^{* * *}$ & $0.076^{* * *}$ & $0.094^{* * *}$ & $0.072^{* * *}$ \\
& $(0.011)$ & $(0.009)$ & $(0.011)$ & $(0.009)$ \\
Perc. risk (asset provided) & $-0.029^{* *}$ & $-0.026^{* *}$ & $-0.043^{* * *}$ & $-0.053^{* * *}$ \\
& $(0.011)$ & $(0.010)$ & $(0.010)$ & $(0.010)$ \\
Investment horizon & 0.000 & $0.013^{* * *}$ & 0.003 & $0.014^{* * *}$ \\
& $(0.005)$ & $(0.004)$ & $(0.004)$ & $(0.004)$ \\
log(Investment amount) & -0.011 & $-0.030^{* * *}$ & -0.010 & -0.012 \\
& $(0.011)$ & $(0.010)$ & $(0.010)$ & $(0.010)$ \\
Stock market participation & $-0.071^{* *}$ & -0.022 & 0.021 & -0.033 \\
& $(0.034)$ & $(0.041)$ & $(0.030)$ & $(0.038)$ \\
Male gender & 0.047 & $0.119^{* *}$ & -0.032 & 0.048 \\
& $(0.035)$ & $(0.048)$ & $(0.032)$ & $(0.041)$ \\
Age & -0.000 & -0.001 & 0.000 & 0.000 \\
Education & $(0.001)$ & $(0.001)$ & $(0.001)$ & $(0.001)$ \\
Constant & 0.011 & $0.030^{* *}$ & -0.007 & -0.002 \\
& $(0.011)$ & $(0.012)$ & $(0.010)$ & $(0.012)$ \\
Observations & $0.440^{* * *}$ & $0.421^{* * *}$ & $0.541^{* * *}$ & $0.536^{* * *}$ \\
Adjusted $R^{2}$ & $(0.127)$ & $(0.131)$ & $(0.125)$ & $(0.125)$ \\
\hline
\end{tabular}

This table reports OLS regressions of the chosen allocation. The basic condition is omitted in both regressions. The dummy for the dominating asset shows the respective difference to the basic asset. Regression (1) analyzes the effects for the high financial literacy group, regression (2) the effect within the low financial literacy group. Regressions (3) and (4) show the same analysis for the named assets. Standard errors are in parentheses. ${ }^{*}$ indicates significance at the $10 \%$-level, ${ }^{* *}$ at the $5 \%$-level, and ${ }^{* * *}$ at the $1 \%$-level. 


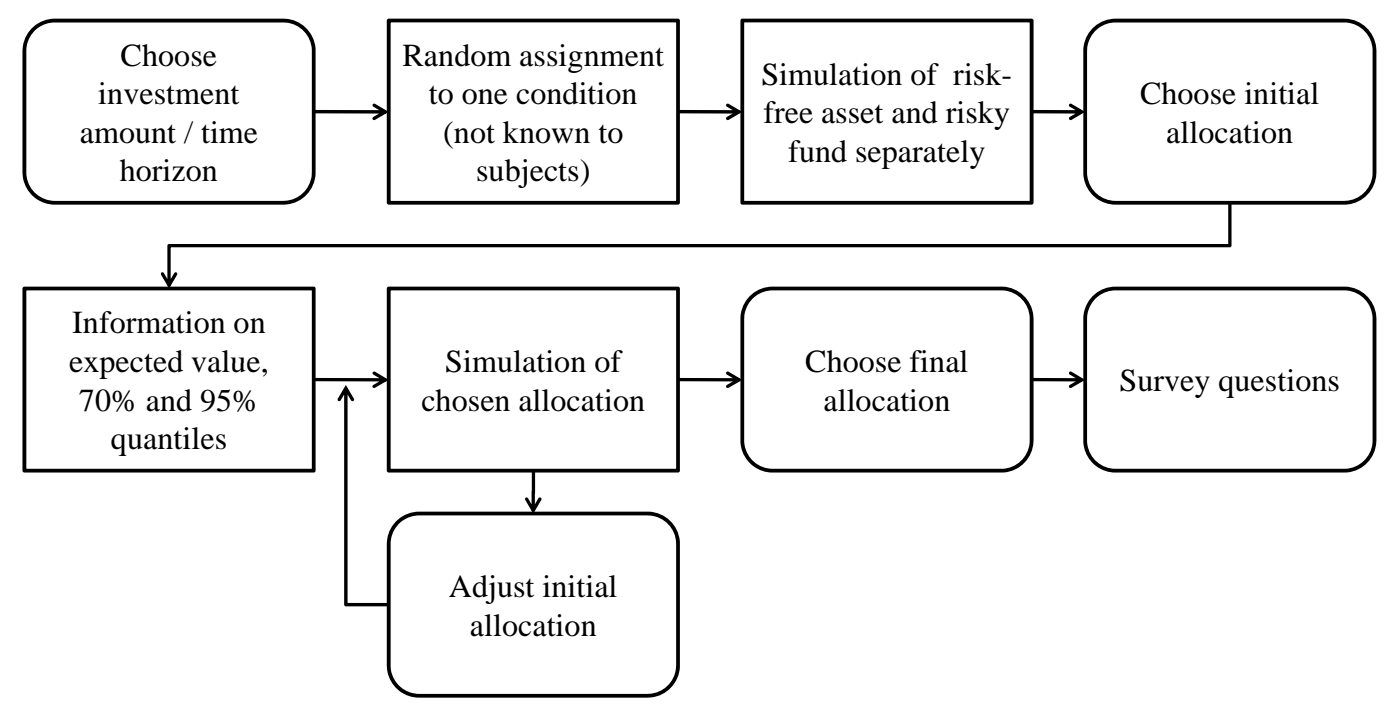

Figure 1: Information given and decisions taken

This figure gives a graphical overview of the experimental design. Decisions which participants have to take are in round boxes, the information they are provided with is in square-cut boxes. 


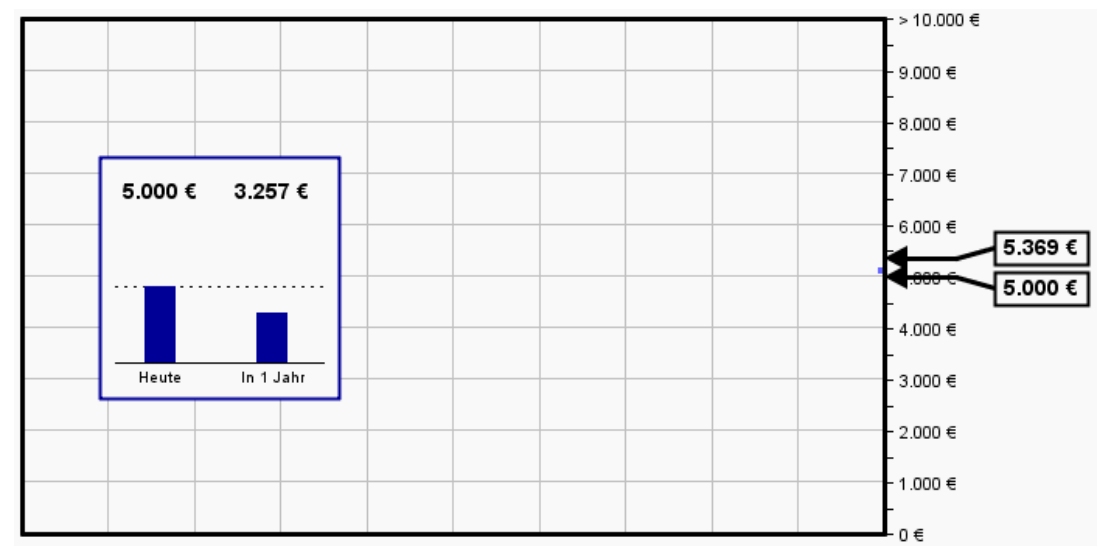

(a) Simulation

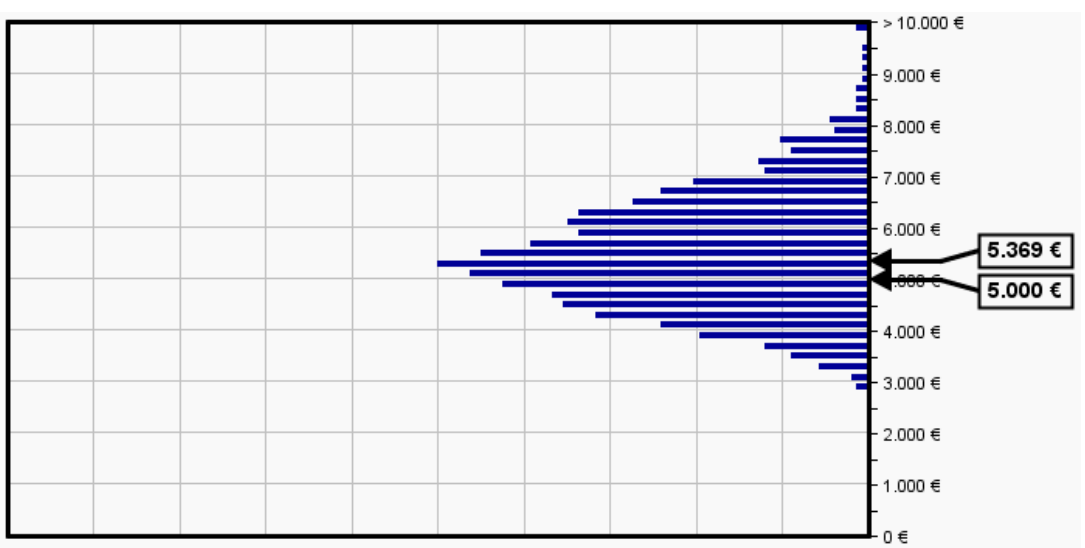

(b) Complete distribution after simulation

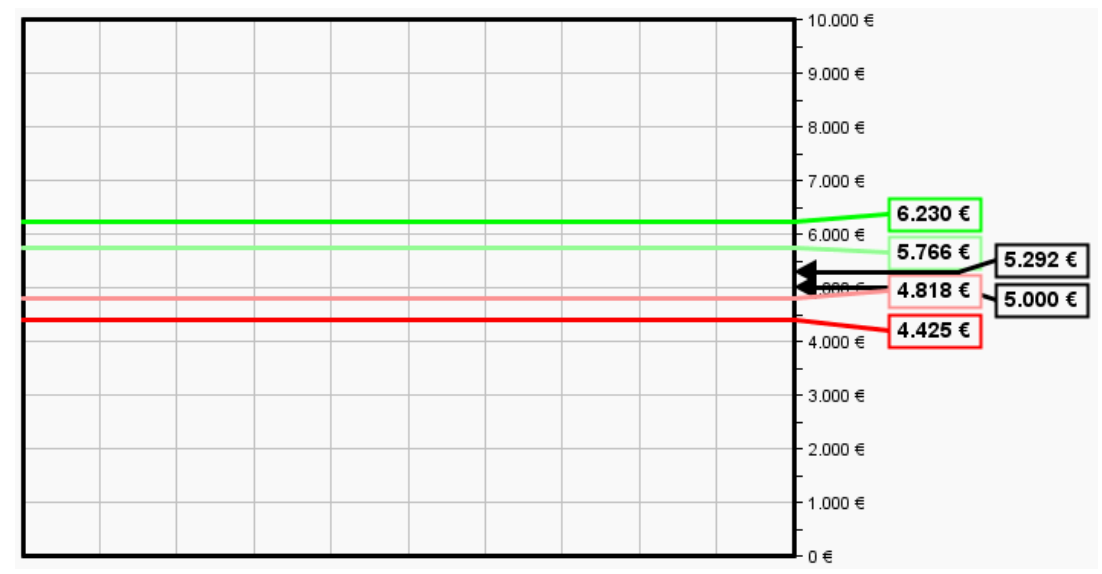

(c) Lines indicating $70 \%$ and $95 \%$ intervals

Figure 2: The risk simulation tool

These figures illustrate the simulation tool. Figure 2(a) shows how single outcomes are drawn during the simulation process, figure 2 (b) shows how the full distribution looks like when the simulation is completed, and figure 2(c) shows the lines indicating important intervals of the respective distribution. 


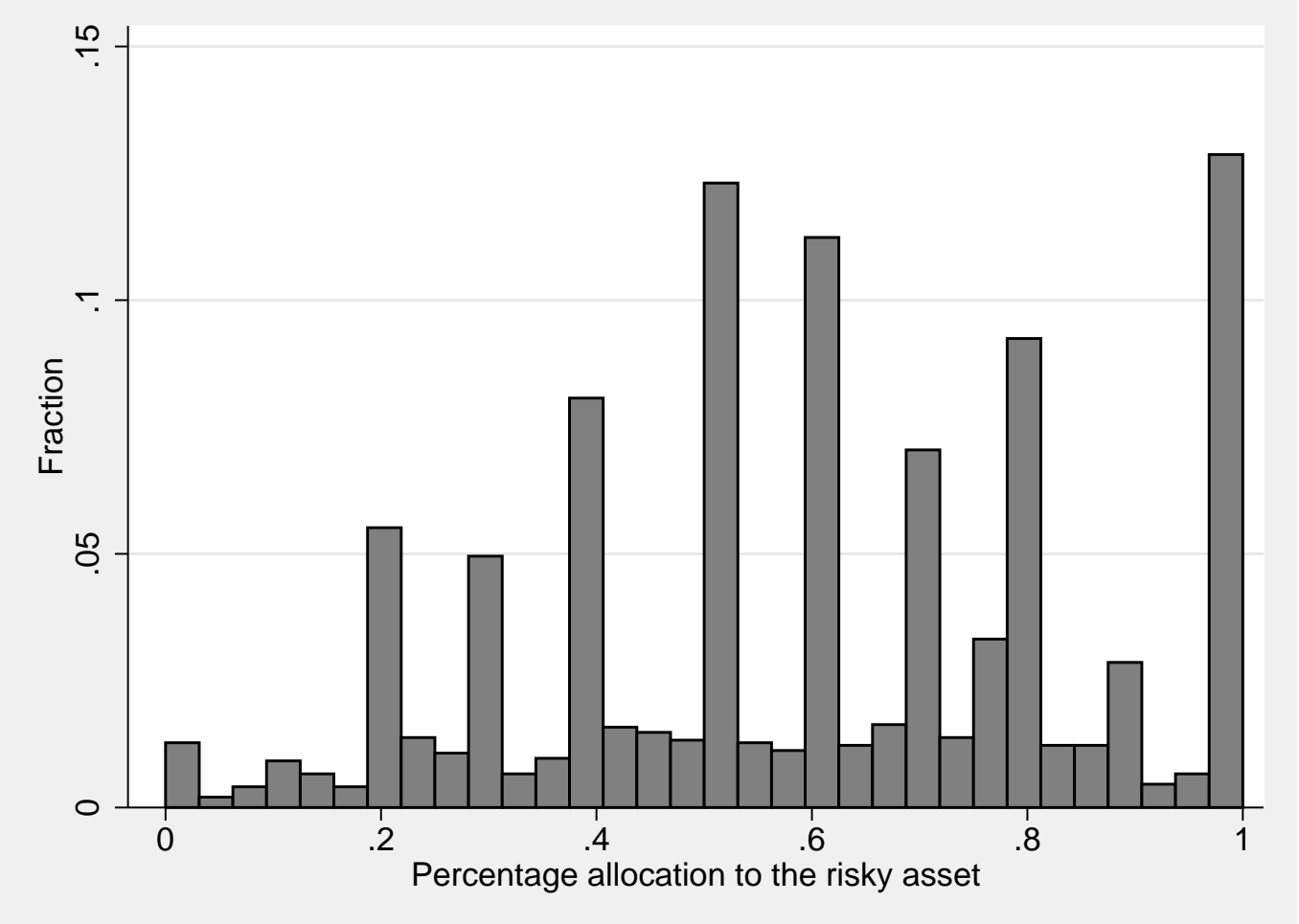

Figure 3: Histogram of percentage allocations to the risky asset 


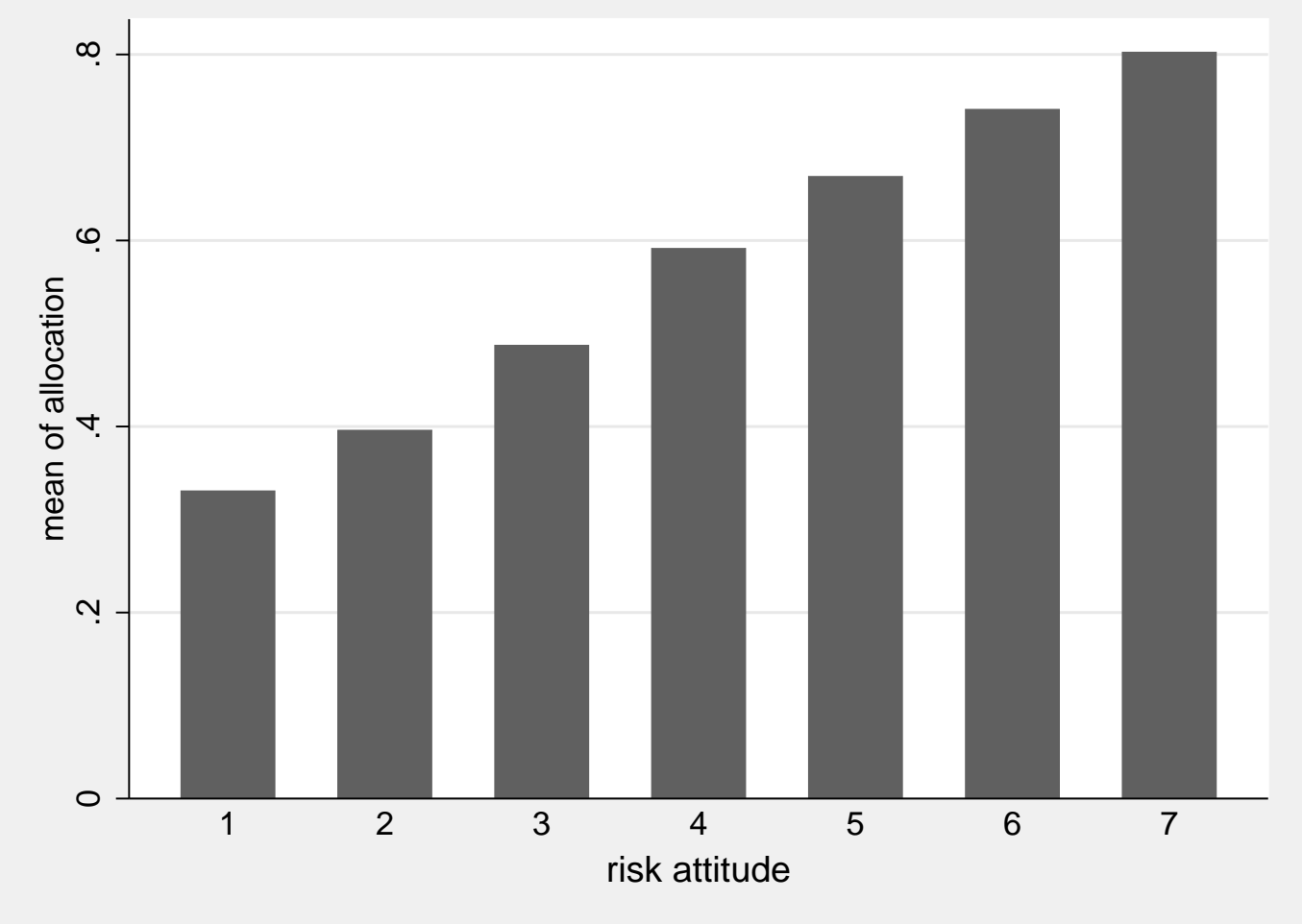

Figure 4: Mean allocation for different stated values of risk attitude (with 1 being the least risky) 


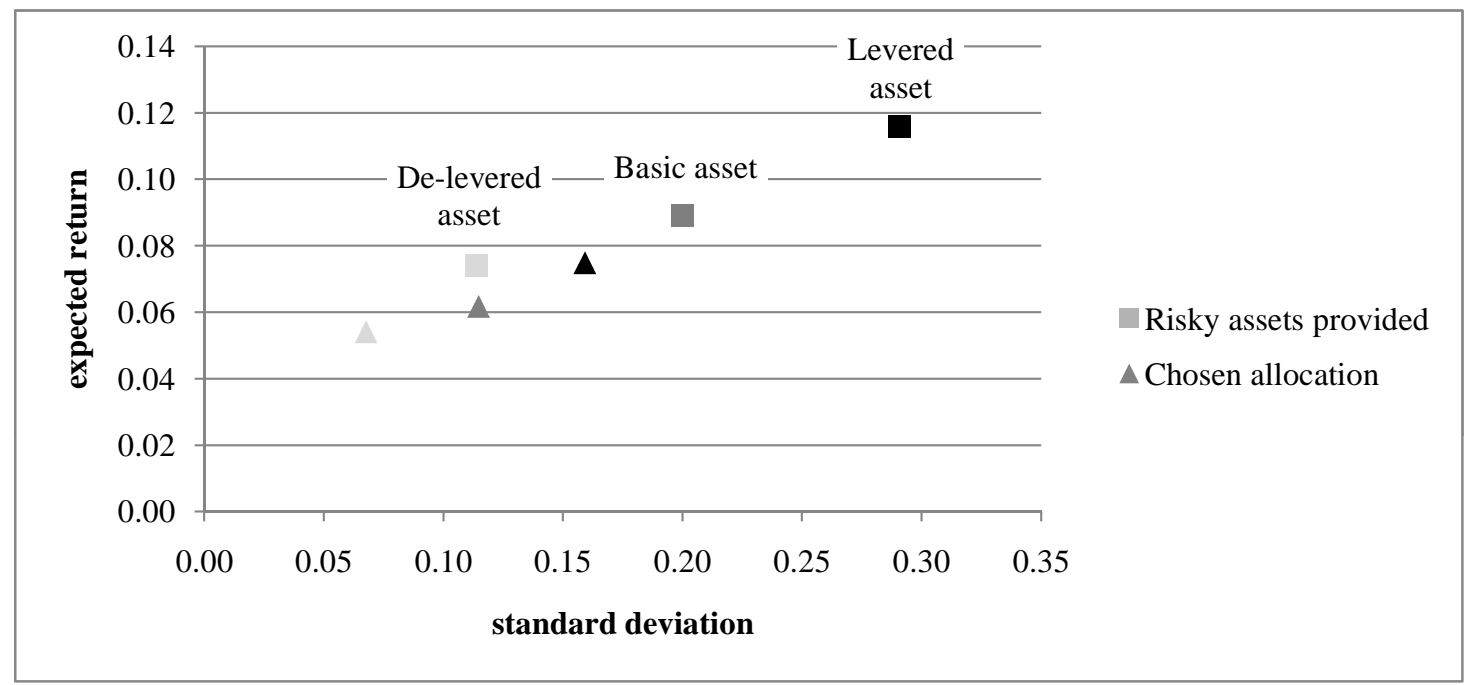

Figure 5: $\mu-\sigma$ diagram of risky assets provided and chosen allocations Figure 5 displays the annual expected return and the annual standard deviation of the he risky assets provided in the main conditions, exemplarily for the five year time horizon. The respective triangles reflect the average risk-return-profile of the portfolios chosen by the subjects within the respective condition. The portfolio returns are calculated by the percentage invested into the risky asset multiplied with its return plus the percentage invested into the risk free asset multiplied with the annual five year interest rate of $2.5 \%$. 


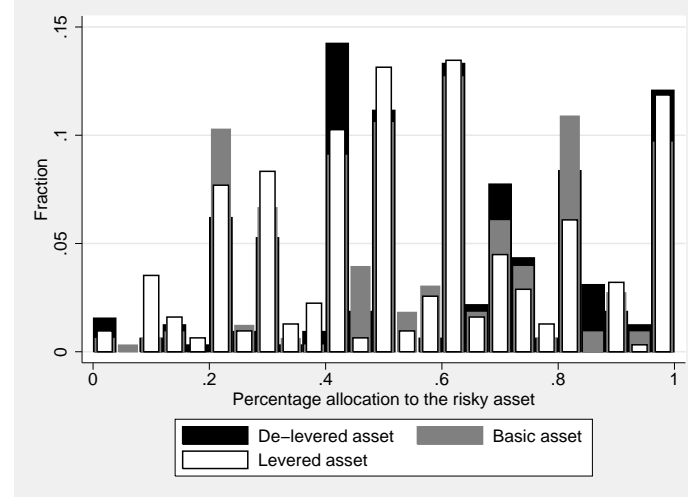

(a) Percentage allocations

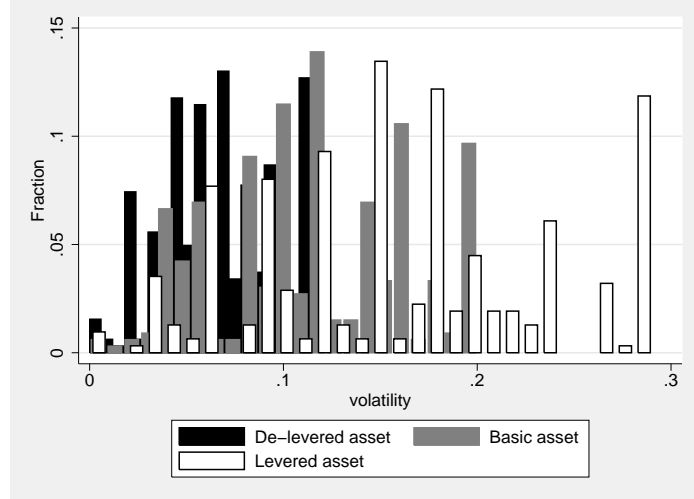

(b) Resulting volatilities

Figure 6: Distributions of chosen portfolios across conditions

Figure 6(a) displays the distribution of allocation to the risky asset in $\%$ of participants over conditions. Figure 6 (b) displays the distribution of the resulting chosen volatility to the risky asset in $\%$ of participants over conditions. As the maximum volatility differs between conditions, participants in the levered condition could choose from a broader volatility range (0-29\%) as compared to participants in the de-levered condition $(0-11.4 \%)$ 

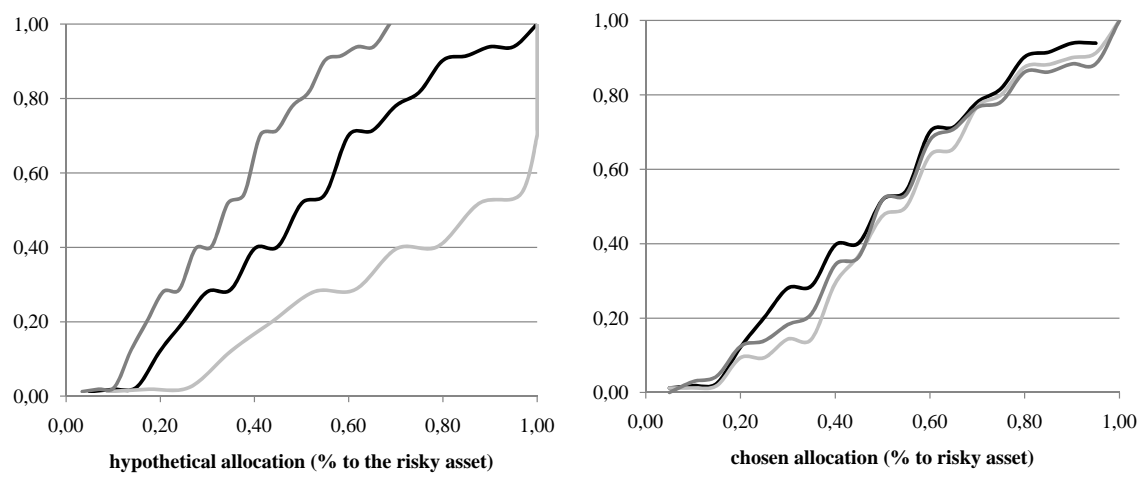

— Basic asset $\quad$ De-levered asset $\quad$ Levered asset

(a) Full sample
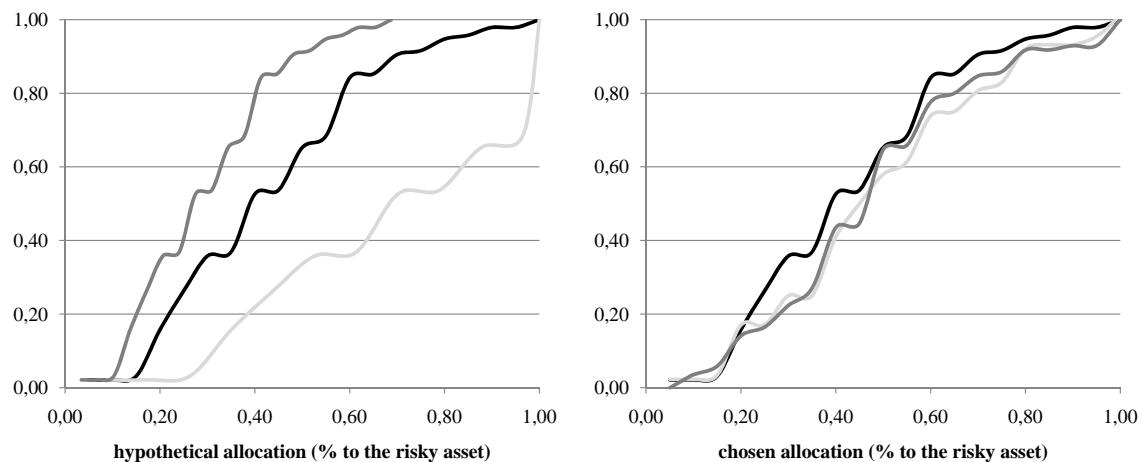

—Basic asset —De-levered asset — Levered asset

(b) Risk attitude 1-4 only

Figure 7: Cumulative distribution functions of percentage allocations to the market portfolios

The left part of figure 7(a) displays the hypothetical cumulative distribution functions (CDFs) of allocations to the risky asset. The hypothetical CDFs are calculated based on the chosen allocations to the basic asset and reflect how the distribution of allocations to the de-levered or the levered conditions respectively would look like if participants chose the same portfolios (in terms of risk and return) as in the basic condition. The right part of figure 7(a) shows the empirical allocation - what participants really have chosen - for all three conditions. Figure 7(b) also shows hypothetical and empirical CDFs for a subgroup of participants with risk attitude between 1 and 4 (on a 1-7 scale, where a higher number indicates a lower risk aversion). 